University of Redlands

\title{
A Multi-touch GIS-based Tour for Museum Exhibits
}

\author{
A Major Individual Project submitted in partial satisfaction of the requirements \\ for the degree of Master of Science in Geographic Information Systems \\ by \\ Yaser A. Albursaid \\ Mark Kumler, Ph.D., Committee Chair \\ Douglas Flewelling, Ph.D.
}

July 2012 
A Multi-touch GIS-based Tour for Museum Exhibits

Copyright (C) 2012

by

Yaser A. Alburshaid 
The report of Yaser Abdulla Alburshaid is approved.
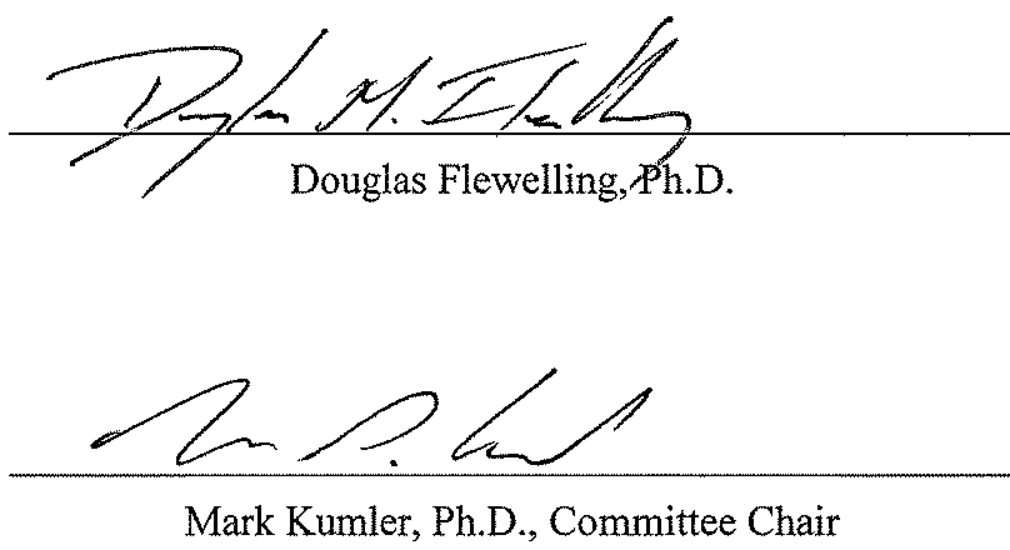

July 2012 



\section{Acknowledgements}

Thank you Allah for all the graces and success, I would not be able to finish this project without your will.

I would like to thank His Excellency the Minister of Interior-Kingdom of Bahrain, Sheikh Rashid bin Abdulla Al-Khalifa, His Excellency the Minister of Housing-Kingdom of Bahrain, Engineer Basim AlHamer, Lt. Col Waleed AlHamden for the great opportunity and guidance that enabled me to study Masters in Science in Geographic Information Systems at University of Redlands, USA.

To my parents, thank you for your unconditional support and unlimited love. Thank you for your prayers. I am honored to have you as my parents.

To my soul mate, fiancée, and only love, Noor, thank you for your support and patience.

I would like also to thank the University of Redlands and the faculty for the full support and guidance that enabled me to accomplish this project, especially the diligent advisor Mark Kumler, Ph.D., for his guidance and efforts.

Thank you All 



\begin{abstract}
A Multi-touch GIS-based Tour for Museum Exhibits
\end{abstract}

by

Yaser Abdulla Alburshaid

Nowadays, museums are continually coping with current advanced technologies to enhance communicating and learning journey for visitors. From this point of view, San Bernardino County Museum (SBCM) found it necessary to adapt a new approach by representing geological exhibits - "geological wonders" - into a rich and interactive experience to the museum visitors and guests.

A system called Multi-touch GIS-based Tour of San Bernardino Geological Wonders is developed that help SBCM to do so. The system works on multi touch tabletops that allow users to interact with three-dimensional spatial representations of geological wonders as if it is in their hands, and virtually fly from one geological wonder to another. In addition, the system lets visitors explore various spatial and contents in such a way that enhances the museum's learning experience and retention of knowledge, and encourage visitors to inspect geological wonders in the field. It also performs some geographic information system analysis to increase understanding and visualization of the wonders. 



\section{Table of Contents}

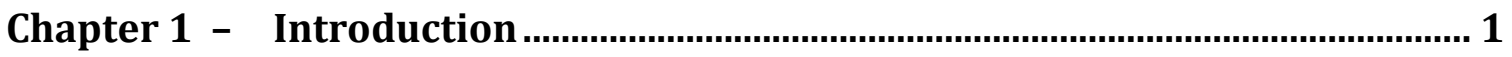

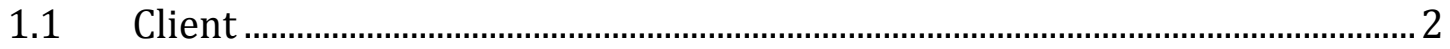

$1.2 \quad$ Problem Statement .............................................................................................

$1.3 \quad$ Proposed Solution ................................................................................................

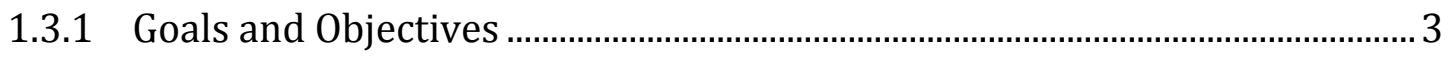

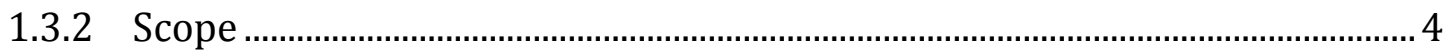

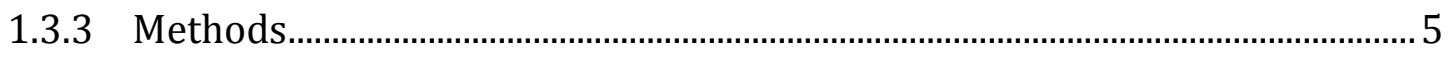

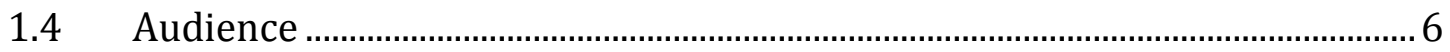

1.5 Overview of the Rest of this Report .................................................................

Chapter 2 - Background and Literature Review................................................ 9

2.1 An Overview of Virtual Reality Systems ...........................................................

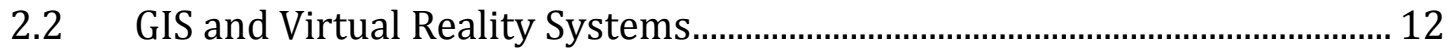

2.3 GIS in Museums.............................................................................................. 14

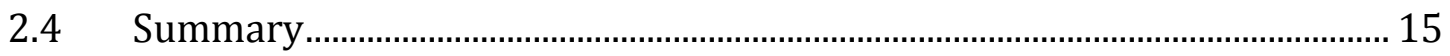

Chapter 3 - Systems Analysis and Design ……...............................................17

3.1 Problem Statement .......................................................................................... 17

3.2 Requirements Analysis ........................................................................... 17

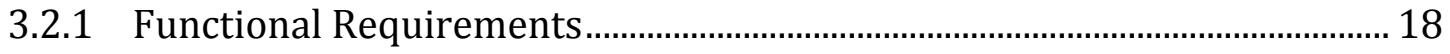

3.2.2 Non-Functional Requirements....................................................................... 19

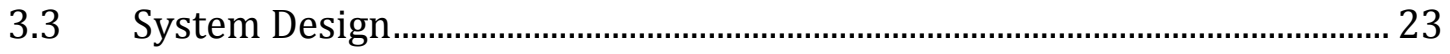

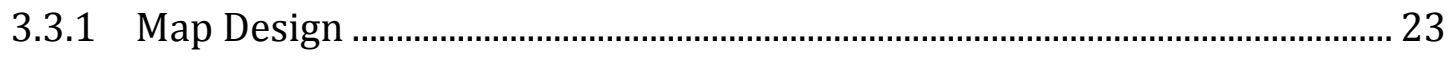




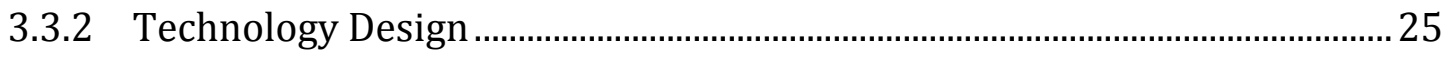

3.3.3 System Architecture Design .......................................................................... 26

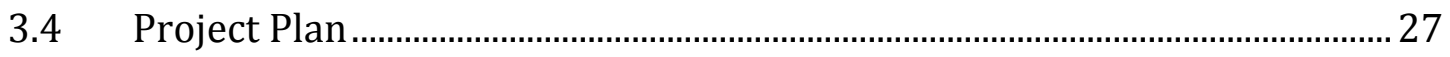

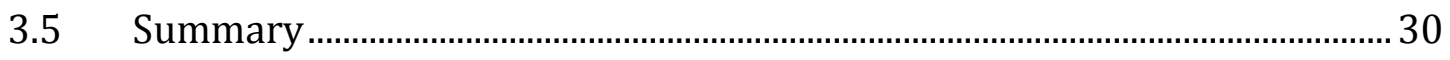

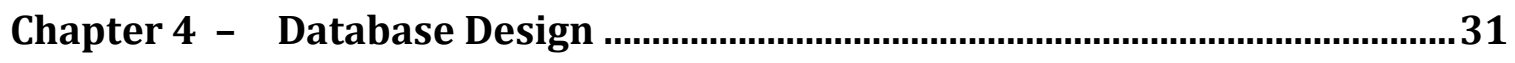

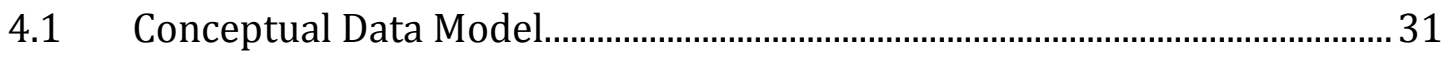

$4.2 \quad$ Logical Data Model...................................................................................... 33

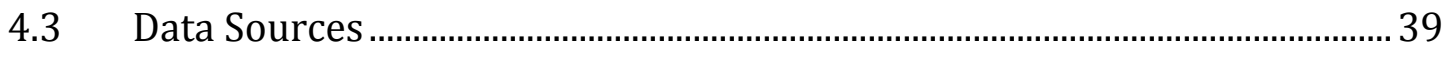

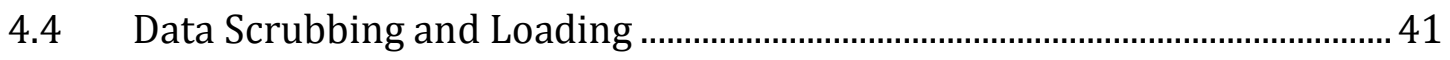

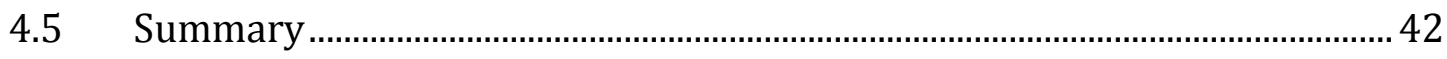

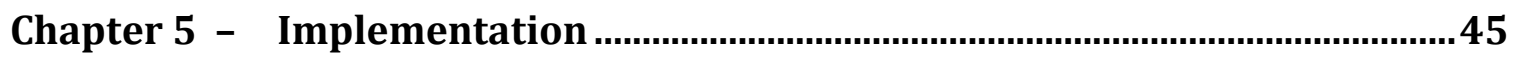

5.1 Prepare the Development Environment......................................................... 45

5.2 Prepare The Geological Areas........................................................................... 47

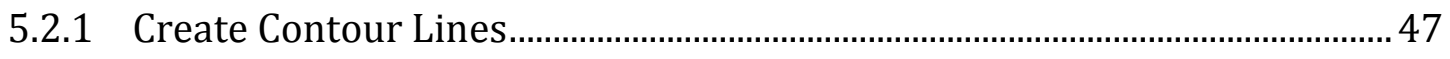

5.2.2 Create Viewshed Analysis ............................................................................ 50

5.2.3 Create the Routes to the Museum ................................................................... 53

5.2.4 Incorporating the Tour's Media Files ............................................................ 54

5.2.5 Preparing the ArcGlobe Document................................................................. 56

5.2.6 Create the Museum's Tour ............................................................................. 57

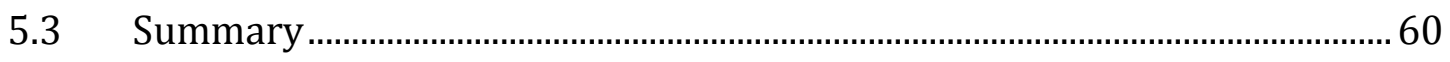

Chapter 6 - Results and Analysis.................................................................61

6.1 The System User Interface Modification …………………………………...... 61 


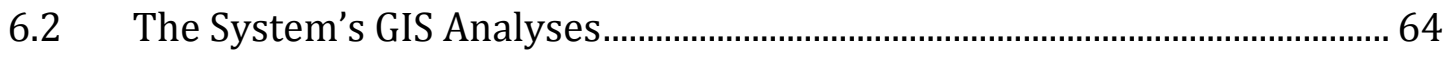

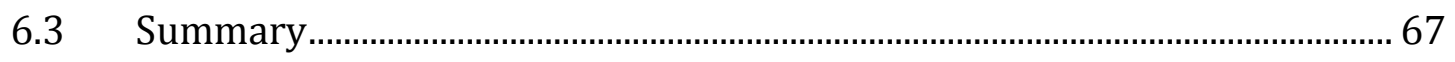

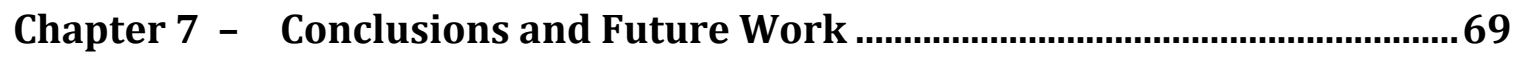

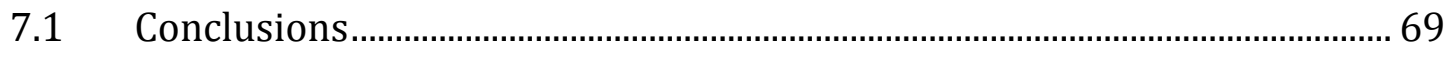

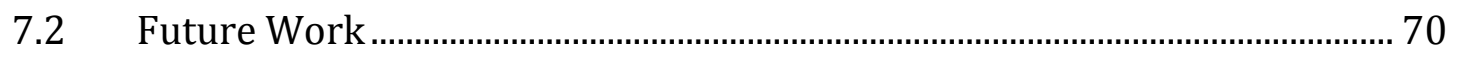

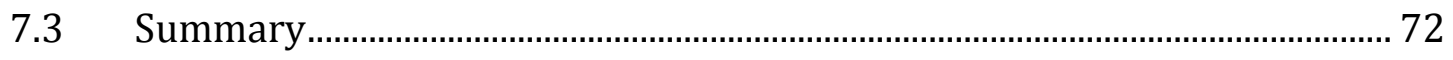

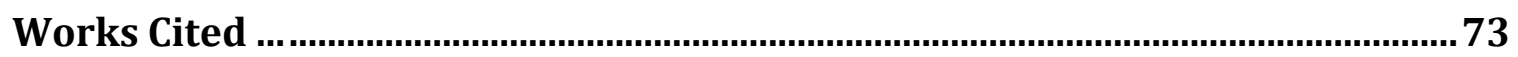

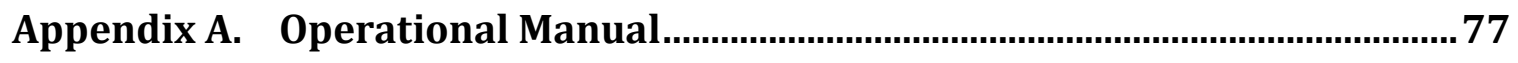





\section{Table of Figures}

Figure 1-1: San Bernardino County Museum ............................................................. 1

Figure 1-2: Rapid Application Development Methodology Diagram ..........................6

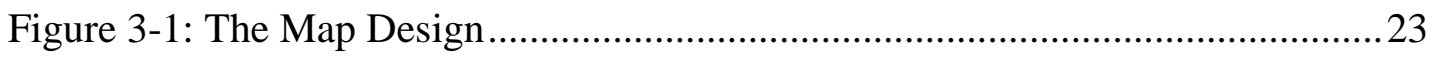

Figure 3-2: The Tour's Navigation Toolbar Design and The Tour Media Player

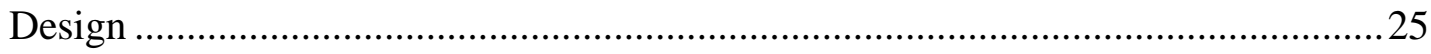

Figure 3-3: The System Architecture Design ........................................................26

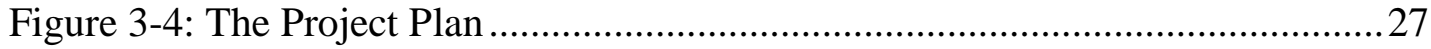

Figure 4-1: The System Conceptual Data Model Diagram ……………....................32

Figure 4-2: The System Geodatabase Contents .......................................................... 35

Figure 4-3: Example of a Feature Dataset that Represent a Geological Area ............36

Figure 4-4: Some Features Labeled in ArcGlobe ……….............................................. 37

Figure 4-5: The Process of Converting the Network Dataset from ArcGIS Desktop

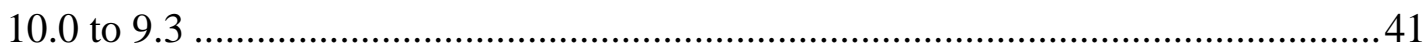

Figure 5-1: TouchTable Calibration Steps...............................................................46

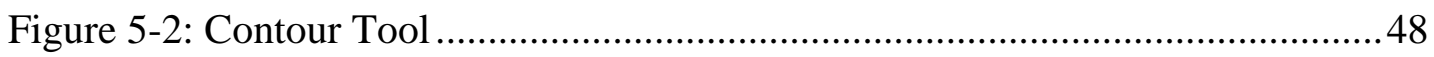

Figure 5-3: Comparison Between the Simplification Algorithms ..............................49

Figure 5-4: Simplify Line Tool .........................................................................5

Figure 5-5: Viewshed Analysis Parameters ...........................................................51

Figure 5-6: The Viewshed Tool ........................................................................52

Figure 5-7: Network Analysis in ArcMap ……………….....................................53

Figure 5-8: The Tour's Media Player...................................................................55

Figure 5-9: Setting Constant Elevation for the Annotation Feature …………….......57 


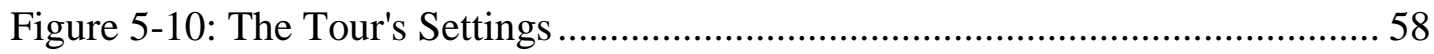

Figure 5-11: Example of a Custom Action ......................................................... 59

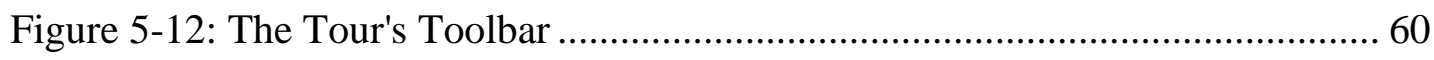

Figure 6-1: TouchShare GIS Software's Menus and Tools .................................. 62

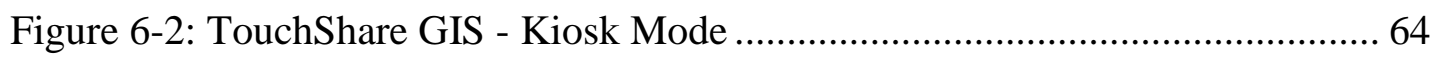

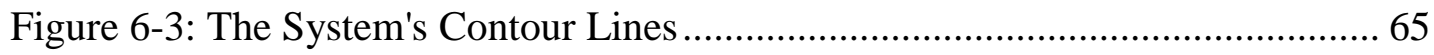

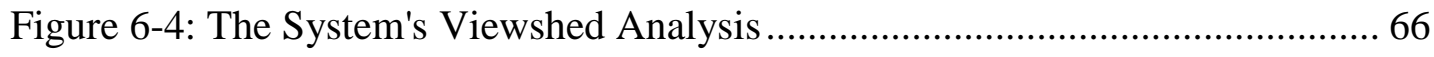

Figure 7-1: Comparison between the system architecture inside and outside the

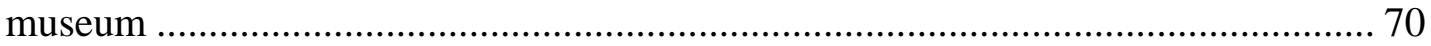

Figure A- 1: Part of the Tour's Media Player Configuration File ............................ 77

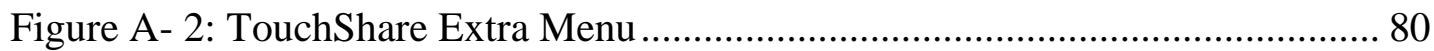

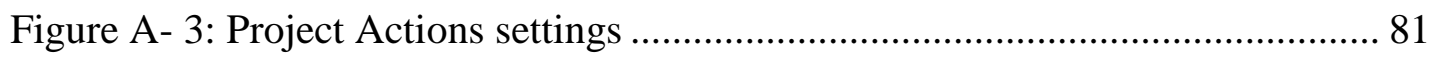

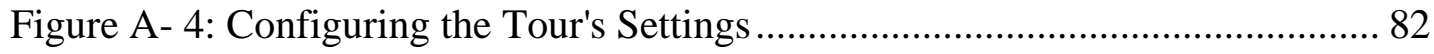




\section{List of Tables}

Table 3-1: Functional Requirements List for the System ........................................ 19

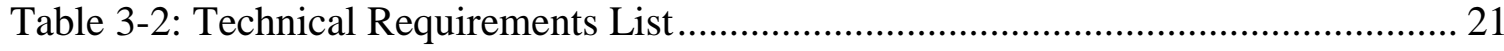

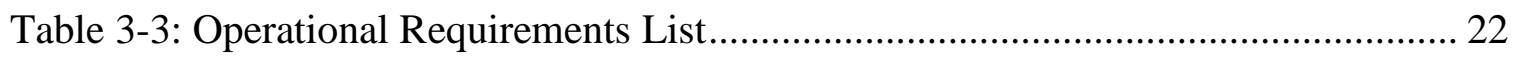

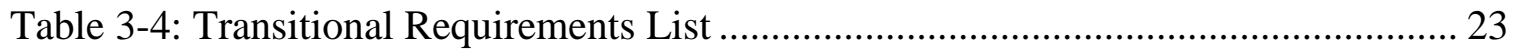

Table 3-5: Map Navigation Multi-Touch Gestures ........................................................ 24

Table 4-1: File and Personal Geodatabase Comparison Summary ................................ 34

Table 4-2: The Database Feature Classes and Main Attributes ..................................... 38

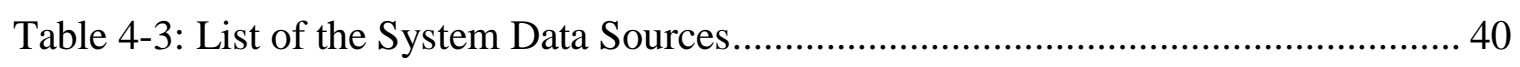

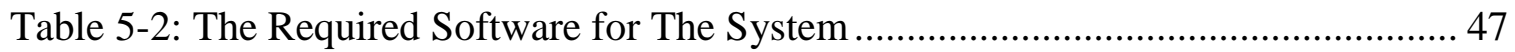





\title{
List of Acronyms and Definitions
}

\author{
SBCM San Bernardino County Museum \\ ISD Information Services Department of San Bernardino County \\ RAD Rapid Application Development \\ WPF Windows Presentation Foundation \\ VR Virtual Reality System \\ VRGIS Virtual Reality Geographic Information System \\ PC Personal Computer \\ DE Development Environment \\ UML Unified Model Language \\ RDBMS Relational Database Management System \\ PCS Projected Coordinate System \\ GCS Geographic Coordinate System \\ IDE Integrated Development Environment
}





\section{Chapter 1 - Introduction}

The Hall of Geological Wonders is part of the San Bernardino County Museum (SBCM) located in Redlands, California. The hall is under construction and planned to open in November 2012. SBCM wants to have a new, distinctive, interactive way to show some of its geological exhibits and collections at the new hall.

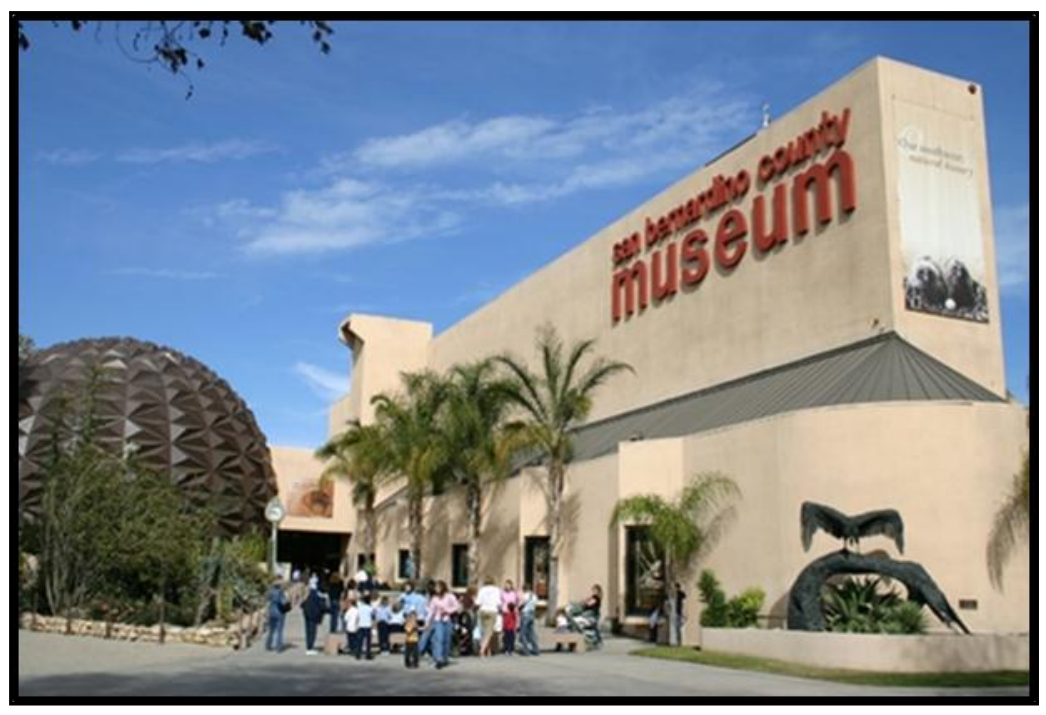

Figure 1-1: San Bernardino County Museum

The purpose of this project was to use a geographic information system (GIS) to represent geological exhibits as three-dimensional features and to use GIS analysis to illustrate some aspects of these exhibits. In addition, the project utilized a large, multitouch tabletop to display a multi-touch GIS-based tour of some geological areas in the southwest region of the United States. The project will increase interactivity between the museum's visitors and the geological exhibits, by developing a rich and dynamic user interface. 
This chapter is comprised of five sections. The first section discusses the project client. The second section presents the general problem. The next section gives a summary of the proposed solution, with subsections describing the project goals and objectives, scope, and methodology. The following section addresses the primary audience for this project; those who would benefit from the solution described in this paper. The last section presents a brief summary of the topics covered in the remaining chapters of this project report

\subsection{Client}

The client of this project is the San Bernardino County Museum (SBCM). Ms. Kathleen Springer, Senior Curator at SBCM, was the primary contact point for the project. She provided the project requirements and information about the selected geological areas for this project. The museum is provided with information technology services, such as GIS services, by the Information Service Department (ISD) of San Bernardino County. Mike Cohen, the ISD's System Development Team Leader, was the contact point for the project's technical services, such as providing GIS data and software, and preparing the multi-touch tabletop for deploying the system. ISD is responsible for maintaining the system.

\subsection{Problem Statement}

The SBCM wanted a new approach to present some of its geological exhibits in a rich and interactive manner for the anticipated hall, The Hall of Geological Wonders, to be added with current conventional approach of modeling part of geological areas in a smaller three-dimensional model. Hopefully, it will attract more visitors. 
The administration of SBCM invested in new technologies to help in developing this new approach. They tried to provide a more intuitive approach to enhance visualization of geological areas and increase interaction between exhibited articles and visitors.

A GIS solution was needed to help in visualizing the geological areas of the region, and give visitors a deeper understanding of these areas.

\subsection{Proposed Solution}

Based on discussions with the client, the proposed solution for the SBCM Hall of Geological Wonders was to develop an interactive, content- rich, three-dimensional virtual tour consisting of stops at several geological areas in the county. It is implemented on multi-touch tabletops linking what is presented in the hall with video clips and interactive flyovers of the landscape. The name of the solution is Multi-touch GIS-based Tour of San Bernardino Geological Wonders.

\subsubsection{Goals and Objectives}

The main goal of this project was to use a new approach to present some of the geological exhibits of San Bernardino County in a rich and interactive experience for museum visitors and guests. Moreover, the proposed system would improve visualization of geological exhibits to increase understanding of information and to enhance retention of knowledge. The system also would extend the learning experience beyond the museum boundaries by encouraging visitors to visit geological areas in the field.

These goals were fulfilled by accomplishing the following objectives. For developing a new way to present the geological exhibits, the system was deployed on a large multi-touch tabletop screen allowing users to interact with three-dimensional spatial representations of San Bernardino County geological areas, and virtually fly from one 
geological area to another. In addition, the system incorporated spatial information like high-resolution imagery and Digital Elevation Model (DEM) data, as well as content like video, audio, pictures, and documents about selected geological areas. It also utilized basic GIS analyses like network analysis and area visibility to enhance the visualization and understanding of geological areas.

\subsubsection{Scope}

To meet the client's goals and objectives, SBCM's system was developed with three major components: data, hardware, and software. One of the most important components of the system was data, which were divided into two categories: spatial data and content data. Spatial data includes high-resolution imagery, DEM, and some vector data. They were provided by ISD of San Bernardino County. The curators of the museum provided content data such as videos, pictures, and documents for each geological area or stop on the virtual tour.

The system works on specific hardware - a multi-touch 45 -inch screen from TouchTable Inc., called TouchTable — to provide interactivity between users and the system by utilizing touch gestures on the TouchTable. A touchtable is a table-sized electronic display with a touch-sensitive screen. The touchscreen allows a user to interact directly with the displayed image, through finger touches and movements, rather than indirectly through a mouse or touchpad. Finger taps replace mouse clicks, finger movements replace mouse/cursor movements, and two-fingered "pinches" and "spreads" allow a user to zoom in and out of a scene. Other multi-fingered actions are often available. These table-sized displays were first developed in 2004 by TouchTable Inc., in Pasadena, California, and the name TouchTable was protected by trademark. With the 
development and marketing of such devices by several other companies -including Microsoft, GestureTek, Ideum, Paravision, and Touchscape -they are now described generically as "multi-touch tabletop devices". Nevertheless, in this report the uncapitalized "touchtable" is used when referring to the device in general terms, while

"TouchTable" is used when referring to the specific device manufactured by TouchTable Inc.

The virtual tour was developed by integrating three different software packages. Esri's ArcGIS 9.3.1 was used to create and manage the spatial data (through ArcCatalog) and to arrange and display spatial data as three-dimensional features through ArcGlobe. Second, a software package, Windows Presentation Foundation (WPF) was used to organize the content data into a rich and interactive manner. Finally, TouchTable's software, TouchShare GIS, was used to develop the stops on the virtual tour and incorporate the three-dimensional geological features with the interactive content data.

\subsubsection{Methods}

This project was developed using the Rapid Application Development (RAD) methodology, designed by James Martin in 1991 "RAD is a development lifecycle designed to give much faster development and higher-quality results than those achieved with the traditional lifecycle." (Martin, 1991, p. 2). It starts with the requirements planning phase by defining the project's business requirements, scope and constraints, and system requirements. Then the user design phase begins by modeling the requirements into inputs, processes, and outputs. This iterative, interactive phase allows the client to discuss, modify, and approve the design of a system. Next, developing a 
system is initiated at rapid construction phase, or prototyping phase. Finally, system deployment and user training are launched at implementation phase. See Figure 1-2.

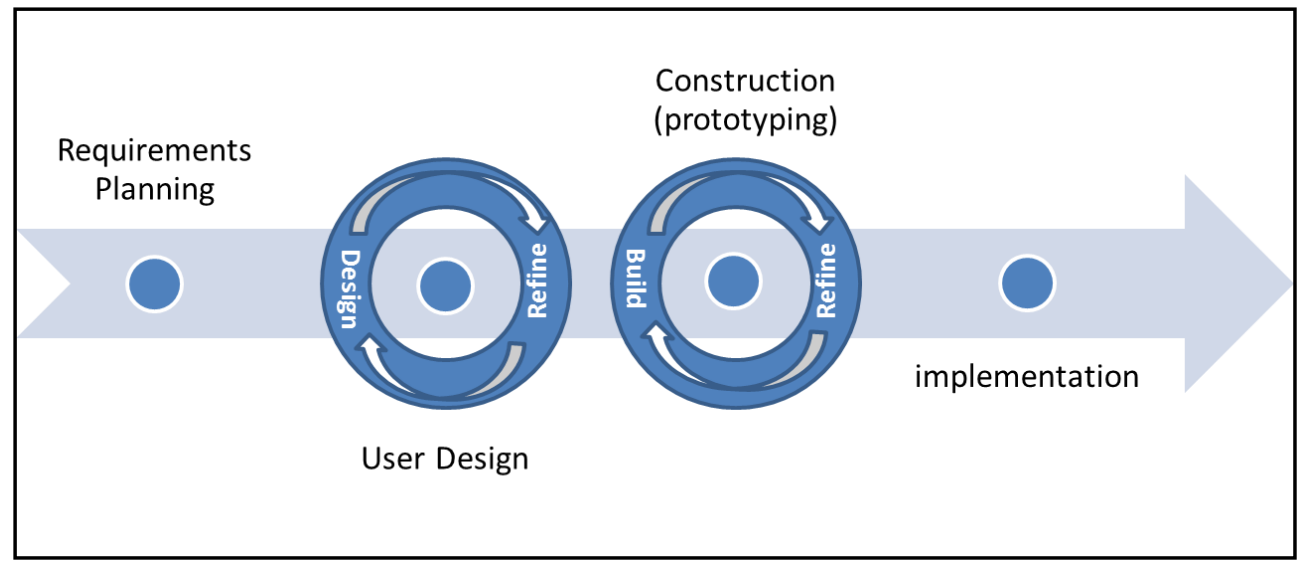

Figure 1-2: Rapid Application Development Methodology Diagram

Several reasons led to the selection of RAD. Most importantly, the timeline of the project was narrow. In addition, the project scope was well defined, limited, and a large part of the required data already existed. Moreover, the project client's representatives were limited to a small number of people — three to four — that were local and readily available for consultation. Finally, the technical architecture of the project was defined and clear. Because RAD designs based on prototyping, iteration, and timeboxing focus attention on delivery on time above all else, RAD fit the project circumstances.

\subsection{Audience}

This report is intended for an audience with an introductory knowledge of GIS and for those who work in the museum discipline. The specific intended audience for this report, the virtual reality system, and the full set of deliverables, was the San Bernardino County Museum. 


\subsection{Overview of the Rest of this Report}

This report is divided into three main categories: project background, overall approach of the project, and the outcome. The first part continues in Chapter Two with background for the project and a review of pertinent literature.

The second part is presented in Chapters Three, Four, and Five as follows: Chapter Three identifies the problem statement, describes the requirements analysis, system design, project plan, and provides a summary of the overall system analysis and design of the project. Chapter Four provides the structure of the database design and includes a conceptual and logical data model, source of the data, and methods for obtaining the data. Chapter Five describes the steps taken to complete the project in satisfaction of the stated project goals and objectives.

Finally, Chapter Six addresses the results of the project implementation and Chapter Seven presents the general conclusions of the project and suggestions for future work. 



\section{Chapter 2 - Background and Literature Review}

Studying available technologies and searching for the best practices implemented in a particular industry are an important step for any project. They help in speeding up tasks by learning from similar, previous projects and by avoiding reinventing the wheel. Knowing the potential limits and benefits of a technology, one can easily identify its suitability to the needs of a client. In addition, studying best practices provides better estimation for planning a project. The Multi-touch GIS-based Tour of San Bernardino Geological Wonders deals with modeling geological areas into three-dimensional features. It also involves virtual reality systems (VR) by including a virtual tour of certain geological areas. This chapter starts with an overview of VR. It discusses possible merging of GIS and VR and the range of applications that result. An investigation into uses of GIS in three-dimensional visualization is discussed. And finally, preliminary research on best practices of implementing GIS in the museum discipline is presented.

\subsection{An Overview of Virtual Reality Systems}

In the last two decades, there have been rapid changes in the ways of representing and visualizing information. New trends have been adopted by educational organizations such as museums, universities, and institutions. These trends are aimed at using technologically advanced systems to enhance understanding and interpretation of information, to increase information effectiveness, and to extend interactions between users and systems. One of these trends is the virtual reality system, which emphasizes the degree of interaction between users and a system. "The term Virtual Reality [VR] emerged in the 1980's as a shorthand for artificial environments in which the user was 
able to 'suspend belief' by accepting that such an environment was real" (Lin \& Batty, 2009, p. 1).

Museums are educational organizations that use virtual reality to provide modern ways of learning while increasing the satisfaction of its visitors. It creates a new kind of museum called a Virtual Museum. This new approach can be used inside or outside museums, such as at conferences and exhibitions; it can also be accessed globally through the Internet. Sometimes it can attract more visitors than a normal museum. In addition, it can allow a virtual "bringing back" of lost heritages. Visitors are able to walk through a reconstructed village, see the development of civilization over time, and virtually fly from one site to another site. It is simply an improved way of presenting existing knowledge to the public (Barcelo, 2002). Moreover, it can allow a museum to exhibit all of its objects, rather than being limited by the physical space of the museum building, or limited with the fragility of the objects (Tsichritzis \& Gibbs, 1991; Lepouras \& Vassilakis, 2004).

Several studies have been conducted on the relationship between teaching and interactive systems, such as VR. There is wide agreement that the use of interactive systems increases learning performance and enhances retention of knowledge (Ang \& Wang, 2006; Hut, 2007; Michael, Zaharias, \& Chrysanthou, 2010).

There are several approaches or methods to use virtual reality systems in presenting information. Three of the significant ones are immersive projection, augmented reality, and virtual reality geographic information system (VRGIS) displays on a multi-touch tabletop, which is referred to as touchtable in this document. Immersive projection technology uses several high-resolution projectors on a wide curved wall to 
provide the impression that visitors are surrounded by the subject matter. This approach has been used widely in museums (Hirose, 2006). The augmented reality technique "involves a representation which mixes part of the real world—either captured by video or directly perceived - with synthetic images" (Brodlie \& El-Khalili, 2002, p. 35). It extends the virtual world to the real world by using monitors, or wearable devices such as head-mounted displays, that superimpose a virtual world on the real world. Augmented reality has been used in museums and expositions (Hirose, 2006). Finally, the use of virtual reality GIS (VRGIS) on touchtable technology, which this project uses, has two main benefits. First, as with augmented reality, it provides two ways of interaction between users and the technology. Second, it allows more than one user to be involved with the technology. "Table-top displays encourage a homier, more-familiar, collaborative atmosphere" (Geller, Sept/Oct 2006, p. 9). There are many examples of using this technology in museums. The virtual tour of the Walls of Nicosia, in The Leventis Municipal Museum in Cyprus, is a good example. The system allows the user to have a virtual tour through a three-dimensional model of the fortifications of Nicosia across the centuries (Michael, Zaharias, \& Chrysanthou, 2010). This technology allows users to interact naturally with a three-dimensional representation of objects such as the Earth's terrain, cities, and buildings. In one especially interesting implementation, it has being used in a pedestrian underpass in Germany to navigate through a virtual globe and explore points of interest (Schoning, 2010).

A recent study presented a comparison between the three mentioned technologies and a traditional approach—using actual exhibited objects—-for presenting information in a museum. It concluded the use of multi-touch tabletop technology surpasses all other 
approaches (Michael, Pelekanos, Chrysanthou, Zaharias, Hadjigavriel, \& Chrysanthou, 2010).

\subsection{GIS and Virtual Reality Systems}

While the idea of merging GIS and VR has become popular in recent years, the first documented fusion was in the early 1990s (Haklay, 2002). "Any given set of data can be converted to many possible pictures. Each such transformation may be said to represent some facet of the data, which one really wants to examine as if it were a geological specimen, turning it over in the hand, looking from many points of view, touching and scratching" (Tobler, 1979, p. 103). Virtual reality geographic information systems fulfill Tobler's vision by adding a more realistic vision to spatial data by allowing a user to inspect and explore the data in hand. The realistic representation of the Earth VR and GIS provide can enhance the Earth visualization (Huang, Jiang, \& Li, 2001).

Haklay (2002) discusses in his paper the possible four levels of VRGIS, based on GIS usage: first, use of plain, two- dimensional maps to build the GIS part in VRGIS; second, using the laws of perspective to provide users the feeling of distance and depth, which is known as perspective view, for example, displaying a DEM with an elevation color ramp in Esri's ArcMap. Another type is three-dimensional VRGIS, which is based on a 3D interactive environment, allowing the user to control the system viewpoint and the representation of the map. The last type is similar to 3D VRGIS, but the GIS environment is immersed by special devices, such as a head-mounted display. Some VRGIS allow users to jump from one level to another as needed (van Maren, Germs, \& Jansen, 1998). 
Many research areas use VRGIS: urban planning, military simulation and intelligence, archaeological modeling, education, and geographic visualization (Huang, Jiang, \& Li, 2001; Koller, Lindstrom, Ribarsky, Hodges, \& Faust, 1995). Any system must have characteristics that distinguish it from others. Thus, VRGIS has specific properties as summarized by (Faust, 1995) and (Haklay, 2002):

1. It provides highly realistic representations of real geographic areas.

2. It is based on traditional GIS databases.

3. The user should be able to move freely around selected geographic features by navigating or orienting the map.

4. Users are allowed to perform GIS functions, such as select, query, and spatial analysis.

5. Visibility functions must be part of VRGIS system.

6. The integration between VR and GIS is loosely coupled.

The last property however has been extended in recent years to include tightly coupled integration thanks to the advancement of hardware and software.

Looking to those properties, a very close symmetry between VRGIS and 3D GIS was found. In addition, looking to the current 3D GIS software, like Esri's ArcScene, ArcGlobe, and Google Earth, they cover all of the VRGIS properties. Thus, they can be considered as a VRGIS. The current progress in 3D graphics processing and efficient terrain visualization algorithms combined with current methods of organizing geographic information led to the development of GIS visualization systems that can be described as Virtual GIS (Koller, Lindstrom, Ribarsky, Hodges, \& Faust, 1995). 


\subsection{GIS in Museums}

Museums collect, document, preserve, and exhibit natural and man-made objects from different time periods. Those objects have geographic location and representation. As a result, the need for a system to maintain and manage the objects' geographic information is increased, especially as some museums keep thousands of exhibited articles. They found a solution to their need in GIS.

There are several possible applications of GIS in museums. One is to keep track of exhibited objects' geographic information. For example, the location where an archaeologist found an object, the possible origin of the object, and the current location within the museum can all be geo-referenced using GIS. The Museum of Shrewsbury in Britain uses GIS for that reason (Boyd, 1999). Each object has a record in its GIS system. The museum staff use these records to answer different questions from visitors such as the location of a specific fossil, distance between a certain city or road and an exhibited article, or the number of objects found in a certain village. All those questions were hard to answer before using GIS.

Another use of GIS is to allow researchers to examine and interpret data from older archaeological collections in museums (Woert, 2011; Garcia-Milagros \& Funk, 2010; Boyd, 1999). It can help researchers discover patterns of the distribution of artifacts or fossils in a certain area. Moreover, it provides a mechanism to locate new archaeological sites or explore existing ones. Studying these data can also help explain archaeological theories using GIS tools (Richards, 1998). In addition, possible relations between old civilizations can be uncovered by studying the data in a GIS framework. 
Sometimes museums are concerned not only with collecting and recording information about fossils or artifacts, but the big picture, or the location where they found the collection, such as a decayed building, territory, or landscape. Modeling and visualizing these locations can help better interpret museum collections. GIS provides powerful tools to model these locations. In addition, it allows performing different analysis types such as three-dimensional analysis or spatial analysis. The results of these analyses can provide a complete picture that can help archaeologists and researchers visualize and understand the locations. Moreover, those models can be exhibited in museums as virtual reality systems that allow visitors to investigate and navigate them.

\subsection{Summary}

This chapter highlights pertinent research done in the study for this project. It started with an overview of virtual reality technology, emphasizing the incorporating of this technology in the museum industry. It also summarized three types of virtual reality systems: immersive projection technology, augmented reality, and VRGIS displays on touchtable, which surpasses the others type in term of user interactivity. The latter technology was chosen to be part of the project solution. Integration between GIS and Virtual Reality technology is discussed in detail. The ability to create a realistic representation of the Earth makes virtual reality an obvious complementary tool for existing GIS capabilities of modeling the Earth. The levels of integration between the two technologies were presented, in addition to the set of VRGIS properties that were found to be similar to 3D GIS properties. Finally, advantages of using GIS in the museum sector were discussed with a focus on two case studies. The next chapter discusses a 
significant phase of the lifecycle of this project: the system analysis and design phase, which built the structure of the system. 


\section{Chapter 3 - Systems Analysis and Design}

Knowing the project scope or range of capabilities helped in developing an effective plan for GIS implementation. In addition, a deep and clear understanding of client needs is a key to successful GIS project implementation. This chapter revisits the problem statement, then discusses the collection of the client needs and how to analyze them to identify the system functions. Next, designing the system based on the client needs is discussed. Finally, the project plan is detailed, with focus on the system planning lessons learned.

\subsection{Problem Statement}

Like most museums today, SBCM is striving to integrate current advanced technologies to better engage visitors and enhance the communication and learning experiences. As a result, the administration of SBCM found it necessary to adapt a new approach to display the museum's exhibits at its new Hall of Geological Wonders, by utilizing state-of-the-art technologies. They wanted to visualize geological exhibits digitally as three-dimensional features. The features will display on a multi-touch tabletop device that allows users to explore them through multi-touch gestures. "The use of tabletop displays has been a common practice, since it provides a collaborative atmosphere, which benefits the users." (Correia, Mota, Nóbrega, Silva, \& Almeida, 2010, p. 117).

\subsection{Requirements Analysis}

After reviewing the reasons that led to initiating this project, a requirements analysis was initiated to obtain a thorough and detailed understanding of the museum's needs. It then specified in precise and explicit language those capabilities and functions SBCM's 
system required. The success and the quality of the system were highly dependent on accurately identifying and understanding those requirements.

The Multi-touch GIS-based Tour of San Bernardino Geological Wonders requirements were divided into two categories: functional requirements and non-functional requirements. Functional requirements defined those features and capabilities of the system that specifically satisfy the client needs. Non-functional requirements refer to the conditions under which the system should perform the specified function. They were grouped into technical, operational, and transitional requirements. A standard language was used to rank the requirements as follows: all "should" requirements were mandatory requirements, and all "may" requirements were desirable requirements.

\subsubsection{Functional Requirements}

After several meetings with the client, a list of the core functions of SBCM's system was identified, which considered the user needs from a system perspective. Table 3-1 shows the functional requirements of the system. These requirements include the capabilities of the system that were identified considering potential use cases. In addition, the last two requirements in the table were added as concepts approved by the project committee.

SBCM needed to allow museum visitors to interact with three-dimensional spatial representations of the geological exhibits. In addition, the system should virtually fly from one geological area to another, as if the Earth were in their hands. Users also should be able to explore various spatial information and content information such as video, documents, and pictures, in a way that encourages them to learn more about the geology of the southwestern United States. 
Table 3-1: Functional Requirements List for the System

\begin{tabular}{|c|l|}
\hline Code & \\
\hline FR1 & The system should present selected geological areas in San Bernardino \\
County as three-dimensional features using spatial data. \\
\hline FR2 & $\begin{array}{l}\text { The system should display information about the selected geological } \\
\text { areas, such as documents about the nature of the area, video, audio, and } \\
\text { pictures. These different forms of information should run in a single } \\
\text { interface. }\end{array}$ \\
\hline FR3 & $\begin{array}{l}\text { The system should automatically move from one geological area to } \\
\text { another, showing information about each area separately. }\end{array}$ \\
\hline FR6 & $\begin{array}{l}\text { The system should allow users to choose a specific geological area and } \\
\text { virtually fly to it. }\end{array}$ \\
\hline \hline
\end{tabular}

\subsubsection{Non-Functional Requirements}

Non-functional requirements define the overall qualities and constraints of the system, and involve technical, operational, and transitional requirements that were determined based on potential use cases. 


\subsubsection{Technical Requirements}

The technical requirements for SBCM's system defined minimum conditions under which it must perform. These conditions are divided into software and hardware. The software needed to run the system were Esri's ArcGIS Desktop 9.3.1 with 3D Analyst extension, TouchTable's software, TouchShare GIS 6.2 as a user interface, and a special media player able to play video or view pictures and documents in a single interface. Given the diversity of the museum's visitors, the user interface should be easy to use for adults and children over the age of seven. In addition, all the required software must run on Windows 7 with Windows Framework 4.0.

The hardware needed to run the system was a personal computer (PC) or a laptop that uses a multi-touch tabletop — from TouchTable Company — called TouchTable as a monitor.

A final important aspect of the system was a means for the museum staff to add more geological areas (stops) to the tour. Table 3-2 summarizes the technical requirements for the system. 


\section{Table 3-2: Technical Requirements List}

\begin{tabular}{|c|l|}
\hline Code & \\
\hline TR1 & The system should be easy to use for children of seven years old or more, or \\
& to start the tour in less than one minute. \\
\hline TR2 & ArcGlobe 9.3.1 with 3D analyst extension to visualize geological exhibits \\
\hline TR3 & into three-dimensional features. \\
\hline TR4 & The system must use TouchShare GIS 6.2 as the primary user interface. \\
\hline TR5 & Framewow system should work on Windows 7 Operating System with Windows \\
\hline TR6 & The system should use a multi-touch TouchTable as the input/output device. \\
\hline
\end{tabular}

\subsubsection{Operational Requirements}

The operational requirements for SBCM's system defined the needed conditions to keep the system operational over time. Table 3-3 lists the operational requirements for this project. The system supports ArcGIS Desktop 9.3.1 with TouchShare software 6.2. Any updates to those two software packages are not supported by the system and may cause issues with the system's functions or data. Moreover, the system should be connected to the Internet to access online map services from Esri. Otherwise, some of spatial data may not appear on the system. 
Table 3-3: Operational Requirements List

\begin{tabular}{|c|l|}
\hline Code & \multicolumn{1}{|c|}{ Description } \\
\hline OR1 & $\begin{array}{l}\text { The system should be hosted on a desktop computer connected with multi- } \\
\text { touch TouchTable works as input/output device. The computer should run } \\
\text { ArcGIS Desktop 9.3.1, and TouchShare GIS 6.2. }\end{array}$ \\
\hline OR2 & $\begin{array}{l}\text { The system data should reside on same desktop computer that hosts the } \\
\text { system. }\end{array}$ \\
\hline OR3 & $\begin{array}{l}\text { The system should be connected to the Internet to access online map } \\
\text { services from Esri. }\end{array}$ \\
\hline OR4 & $\begin{array}{l}\text { ISD of San Bernardino County maintains the system. Thus, documentation } \\
\text { of how to operate the system and how to add new geological area shall be } \\
\text { delivered. }\end{array}$ \\
\hline
\end{tabular}

\subsubsection{Transitional Requirements}

The transitional requirements for this project defined what was needed before and after deploying the system for a successful implementation in the production environment. Table 3-4 summarizes those requirements. ISD and the project team were responsible for the system deployment. The system also needed replicas in two different locations in the museum, with the same running platform. Finally, a demonstration for all of the system functions should be conducted for ISD and the museum's curators as training for the system. 
Table 3-4: Transitional Requirements List

\begin{tabular}{|r|l|}
\hline Code & \multicolumn{1}{|c|}{ Description } \\
\hline RR1 & $\begin{array}{l}\text { A 30-minute session should be conducted to demonstrate the system full } \\
\text { functionality. }\end{array}$ \\
\hline RR2 & $\begin{array}{l}\text { Two replicas of the system should be created in two different locations in } \\
\text { SBCM. }\end{array}$ \\
\hline
\end{tabular}

\subsection{System Design}

After the system's functions and capabilities were specified in the system analysis phase, system design phase took over and translated the outcome of the analysis into a technical solution. The design should satisfy all of the system requirements, and make it easy for users to engage the system. The Multi-touch GIS-based Tour of San Bernardino Geological Wonders design was divided into three areas: map, technology, and system architecture design.

\subsubsection{Map Design}

SBCM's system provided a digital, three-dimensional, full screen map to visualize geological features of San

Bernardino County, as shown in

Figure 3-1. The map was shown on

a 45-inch TouchTable. Users are able to interact with the map zoom-in, zoom-out, tilt, and pan -

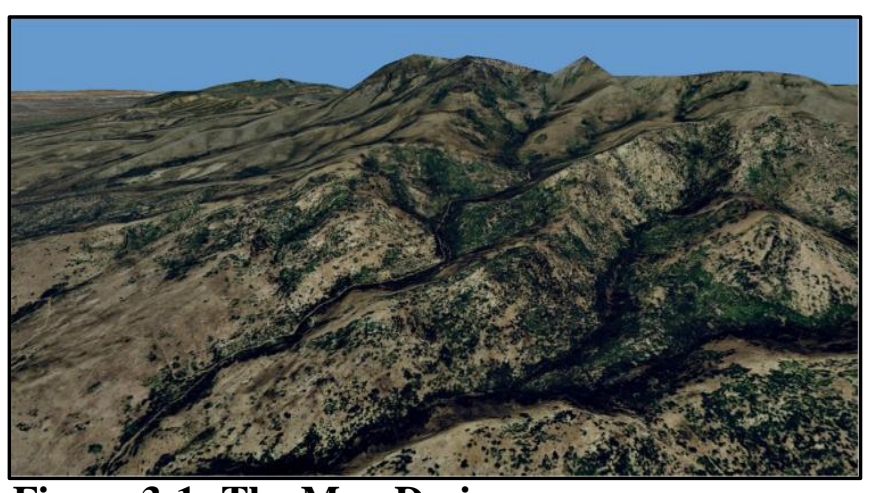

Figure 3-1: The Map Design 
through use of multi-touch gestures that TouchShare GIS provided. Table 3-5

summarizes those gestures.

Table 3-5: Map Navigation Multi-Touch Gestures

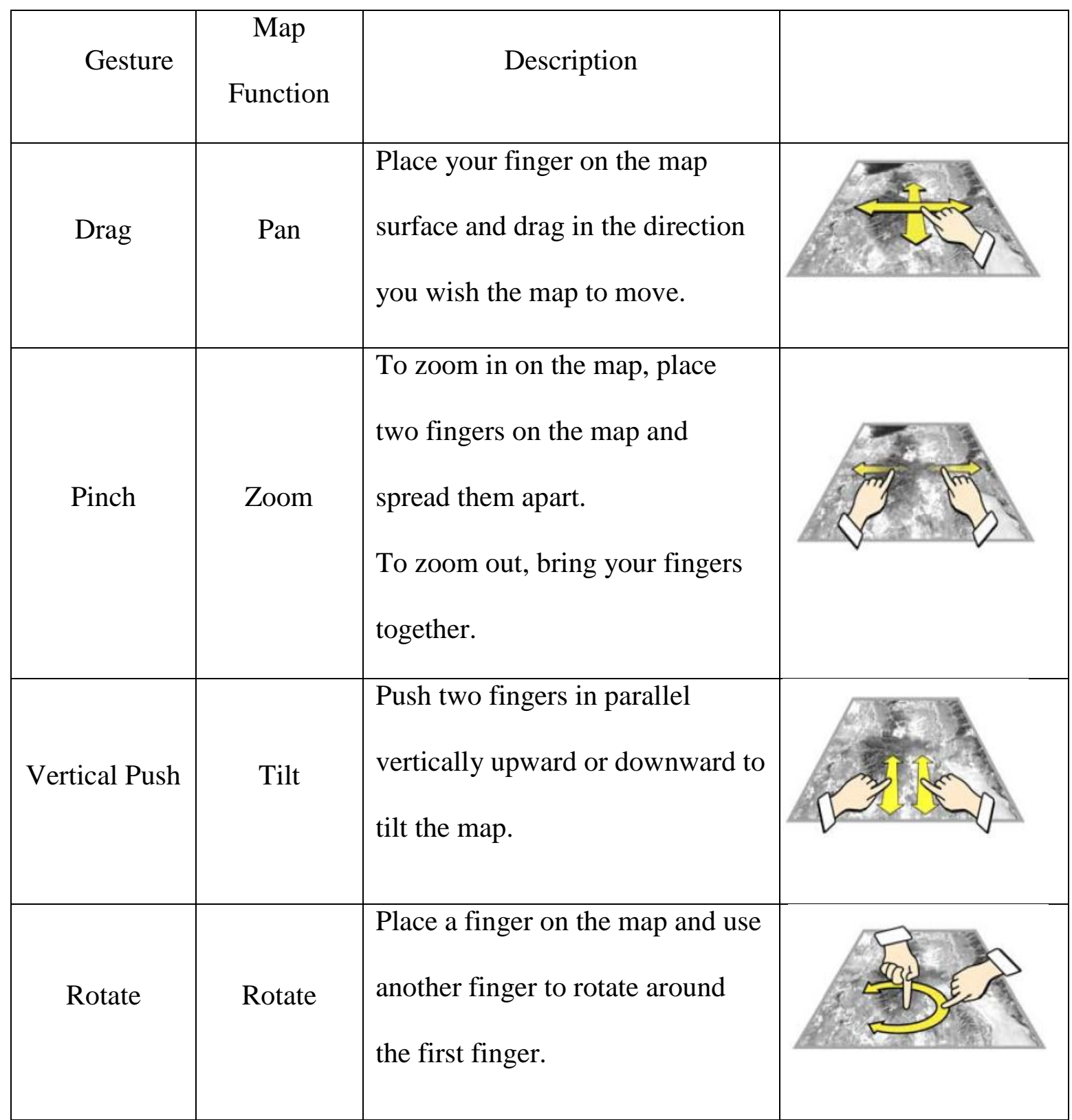

As a result of the system requirements, the map design must be self-explanatory and easy to use, since most of the map's users have no or limited GIS background, and 
they range between children of seven years and seniors of more than 70 years old. Thus, cartography techniques were used to facilitate understanding and interpreting of the map by using common symbologies for the map's features to mimic the real world. For example, blue lines for rivers, and green areas for vegetation. In addition, the map used scale dependencies to show as few layers as possible to describe certain geological areas. Labels are very important parts of any map, and they must be carefully created and placed.

\subsubsection{Technology Design}

The system provided a toolbar to interact with the tour. It allows users to start the tour by moving through the geological areas automatically. In addition, users can select a specific area from bookmarks to fly to. The toolbar also gives ability to jump to the next or previous geological area in the tour. The tour's navigation toolbar is designed to be clear and simple by using common icons indicating the functionality of tools in the toolbar, as shown in Figure 3-2.

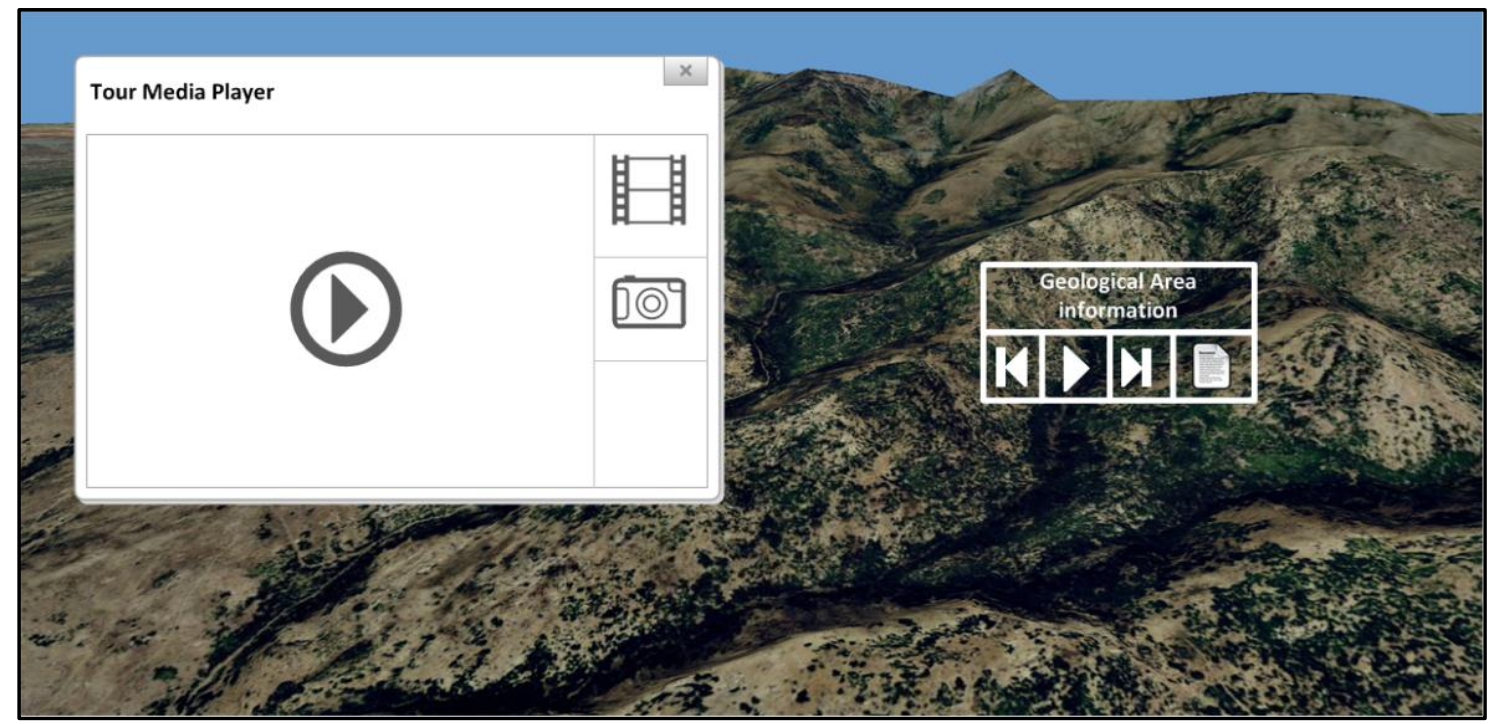

Figure 3-2: The Tour's Navigation Toolbar Design and The Tour Media Player Design 
Moreover, the system provided a media player that can show content information of a geological area, such as video, pictures, and documents. The media player was designed to hide the complexity of viewing different media formats by showing them in a single interface. Users can play a video, then jump to view pictures and documents with a single touch. The player is opened automatically when the tour reaches a geological area that has content information. In addition, as a technical requirement, the system should be able to extend the tour easily by adding new geological areas and their related data - GIS and content data. Consequently, the player was developed in a way to add new video, pictures, or documents easily by editing the player's configuration file.

\subsubsection{System Architecture Design}

The system architecture defined the structure of the system in terms of hardware, software, and supporting tools. It also determined how to distribute the various system components across the architecture.

Figure 3-3 depicts the architectural design of SBCM's system.

The system architecture had two points of view. From a data point of view, both data types resided locally at a workstation. GIS data were organized in a file geodatabase that was managed by ArcCatalog 9.3.1, and content data kept in a folder

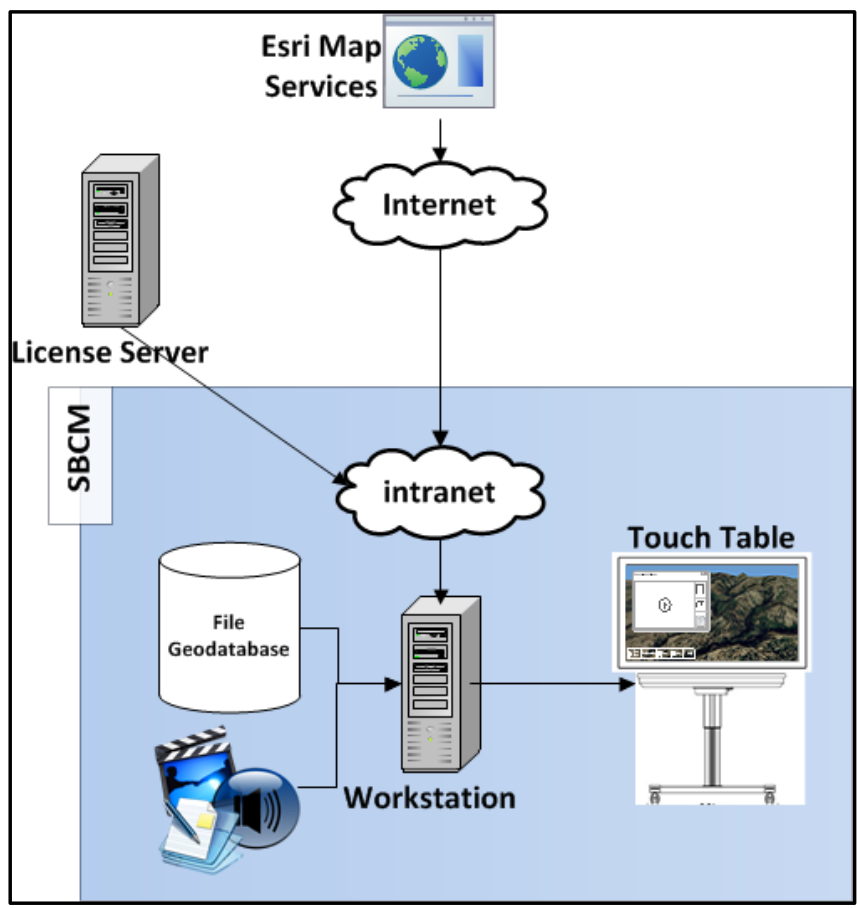

Figure 3-3: The System Architecture Design directory on the same workstation. 
However, the system's map services that reside on Esri web servers were accessed through the Internet. The system displays and renders three-dimensional features, which is a very intensive computer task. Thus, keeping the data local on the workstation was good for the system's performance, yet it can lead to data update issues.

From a software point of view, the workstation should run three software packages:

ArcGIS Desktop 9.3.1 licensed from SBCM's server license; TouchShare GIS 6.2

licensed locally; and a tour media player that was developed using Windows Presentation Foundation 4.0 (WPF 4.0).

\subsection{Project Plan}

The system work plan was divided into seven main phases: project initiation, project planning, requirements collection and analysis, system design, development environment preparation, prototyping, and system deployment. Figure 3-4 shows the full plan.

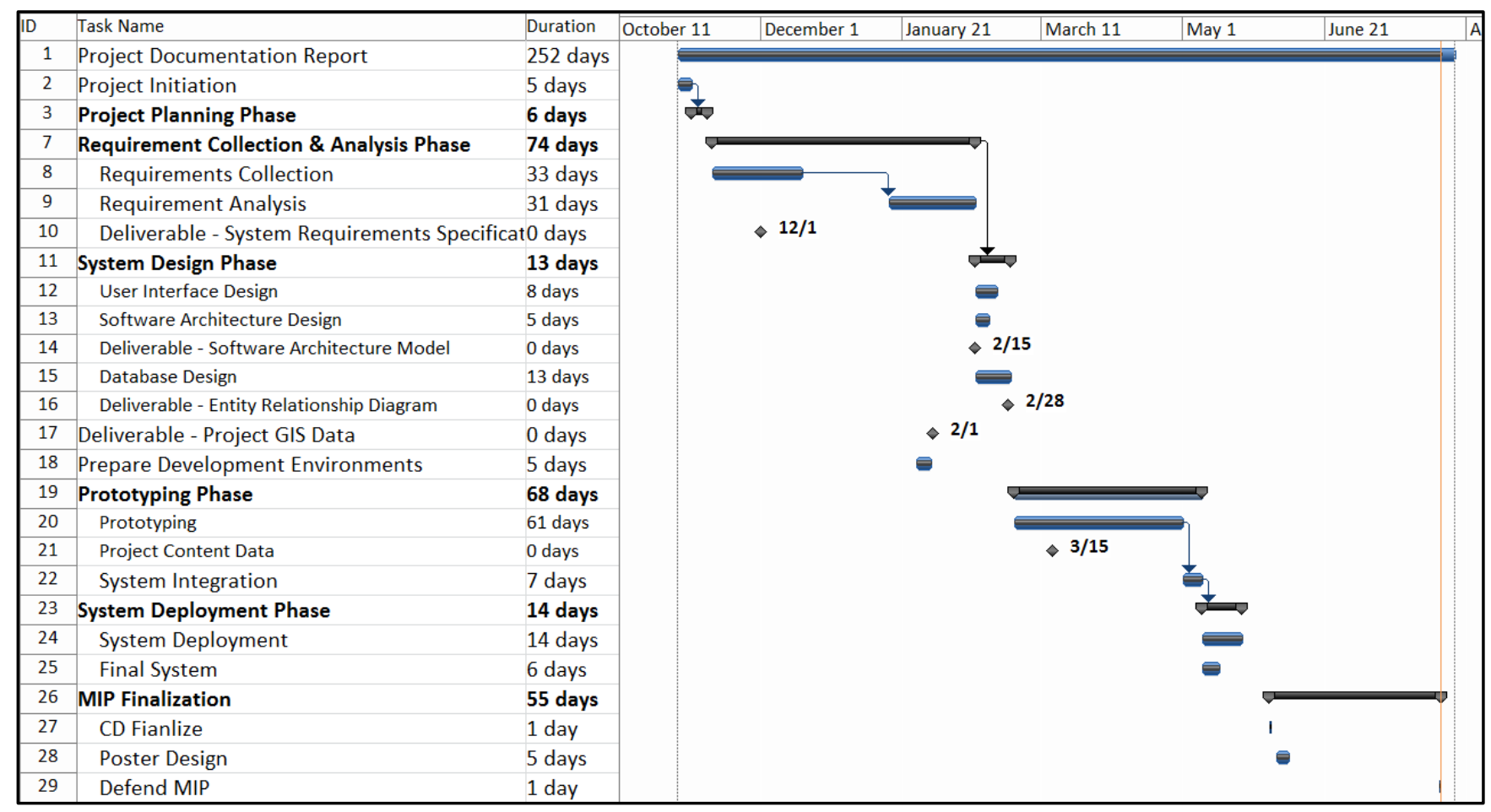

Figure 3-4: The Project Plan 
The following is a more detailed description of these tasks:

- $\quad$ Phase 1: Project Initiation:

The project main structure was defined at this phase. A series of meetings and communications were conducted to identify the statement of problem, project goals and objectives, and project preliminary scope.

- $\quad$ Phase 2: Project Planning:

Before tackling the problem, a plan was created to develop the solution. The project planning was an iterative task that helped guide and manage the project. First, an overview planning and estimation of the project's tasks was created. Throughout the project progress, the plan was modified to reflect the status of knowledge and information of the project. After each plan modification, two outputs were updated: an updated project plan and an updated Workflow Process Diagram.

- Phase 3: Requirements Collection \& Analysis:

One of the most important outcomes of this phase was a functional and nonfunctional requirements list. The client approval for the list was crucial to move ahead with the system design phase. Requirements collection plays a key role in the success of any project. Consequently, a series of meetings with the client were conducted to identify the problem accurately and to gather SBCM's needs. An analysis of those requirements was then performed to clarify and finalize them. A detailed understanding of the client's needs was obtained to define the full set of the system's capabilities and characteristics as the list of functional and non-functional requirements. 
- Phase 4: System Design:

The system design was based on the outcome of the previous phase, and focused on three aspects. First, system architecture targeted the integration of the system's different components. A model was created depicting the architecture. Second, database design was concentrated on how GIS and content data were stored efficiently in the system's database. Finally, user interface design was focused on the layout of the system's screens. A conceptual user interface design was made as a start point, then through the prototyping task the design revised until it reached the client's satisfaction.

- Phase 5: Preparing Development Environment:

Before starting the system development, the development environment (DE) was identified inside the University of Redlands Master of Geographic Information Systems department as a PC and TouchTable. ISD provided all of the required data for DE.

- Phase 6: Prototyping:

In this phase, the construction of the system took place as an iterative task. It involved client feedback after developing each version of the system. An incremental prototyping approach was used to develop the system by dividing the system into three modules: map, the tour media player, and the virtual tour. Each module was developed as a separate prototype. Finally, all the modules were integrated to create the final product. 


\section{- $\quad$ Phase 7: System Deployment:}

The complete system was installed on the client's environment at SBCM. In addition, a small training session was conducted for the museum's curator.

Any plan will likely incur changes during implementation; they can be acceptable or unacceptable. Fortunately, this project had acceptable variations for several reasons. One reason was that sometimes the client did not provide feedback of accepting or modifying some of the project's deliverables such as the functional requirement list, which led to delay on the dependent tasks. However, the prototyping phase took less time than expected due to lack of understanding software, which balanced the schedule. Therefore, the project schedule remained almost as planned except for some small changes.

\subsection{Summary}

This chapter provided an overview of the amount of work needed to develop the solution and complete the project. The system requirements were identified accurately through a series of meetings and effective communication with the client. Those requirements were analyzed through intensive research and studying best practice in order to list all of the system capabilities and characteristics. The system design converted the system functions into sets of conceptual models that facilitated the development of the final product. Finally, the chapter summarized the major tasks of the project plan in detail, and discussed the reasons for plan variations. The next chapter describes an important component of the system: database design. 


\section{Chapter 4 - Database Design}

A GIS-based system employs a special kind of database called a GIS database or geodatabase (Tomlinson, 2011). It has the ability to store and retrieve spatial data efficiently, sort spatial data based on their spatial locations, and maintain spatial relations between special data. In addition, it performs a normal database's tasks of maintaining attribute data.

This chapter describes the conceptual design of the database that was created based on the project requirements, as well as the geographic and attribute data used to run the Multi-touch GIS-based Tour of San Bernardino Geological Wonders. Next, the sources of the listed data and the data collection methods are detailed. Finally, a description of necessary processes to keep data ready to be used by the system is articulated.

\subsection{Conceptual Data Model}

After all the system requirements had been collected and analyzed, a conceptual design model for the required data to fulfill those requirements was designed. The model defined the entities of interest that addressed the project's requirements and specified each entity's attributes and relationships with the other entities. "The conceptual schema is a concise description of the data requirements of the users and includes detailed descriptions of the entity types, relationships, and constraints" (Elmasri \& Navathe, 2004, p. 52). The system's conceptual data model diagram was created using a Unified Model Language (UML) diagram to illustrate the model. The diagram was a high-level abstraction that simplified the complexity of the real world. It also could be used as a communication medium between the development team and the client. This diagram represented the main structure of the system's database. Creation of the diagram involved 
several steps: identifying the data entities, listing their attributes, and linking the related entities. Figure 4-1 illustrates the system conceptual data model.

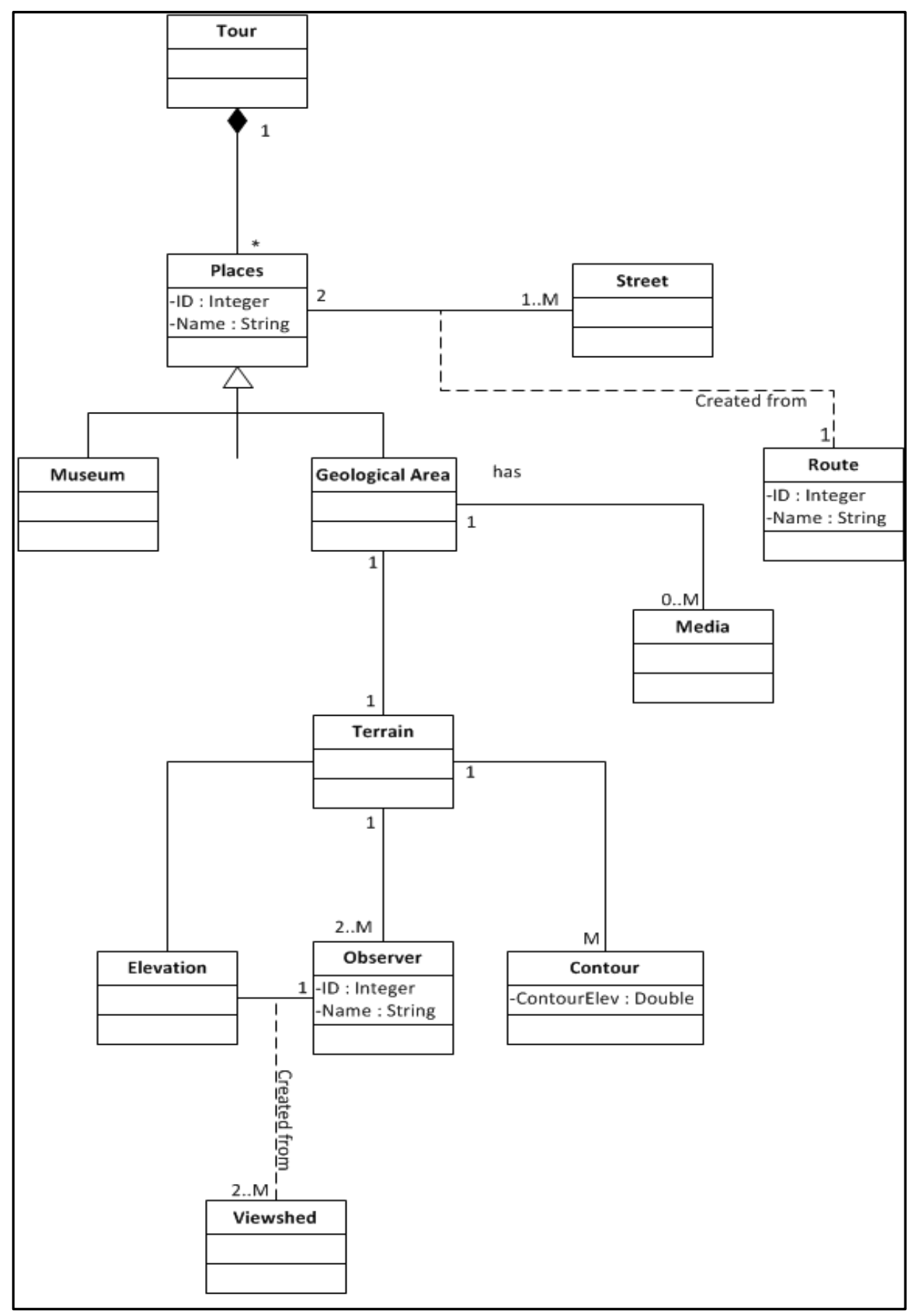

Figure 4-1: The System Conceptual Data Model Diagram 
The diagram shows a composite relationship between the Tour entity and the Places entity; depicting the system virtual tour consisted of one or more geological areas and the museum. The diagram shows relationships between the Geological Area entity and other entities: Media, Places, and Terrain. A one-to-many association relation with the Media entity was created to link each area with its corresponding media elements. The association relationship with the Places entity indicated that the Geological Area entity is a type of Places entity. The last Geological Area entity relationship was the Terrain entity, illustrating that a geological area was represented from a surface terrain that generates elevation, observer, viewshed, and contour lines to be parts of the area. The relationship between Street and Places entities was created to represent the generation of a route between the museum and a geological area, as was requested by the project committee.

\subsection{Logical Data Model}

The logical model of the system's database was derived from the conceptual model. This happened by converting the conceptual entities, attributes and relationships to sets of spatial tables (Feature Classes) and attributes tables (Elmasri \& Navathe, 2004). Tomlinson described this process as follows: "A logical database model must 'describe' a complex version of the real world in a database. Such [a] model not only represents the data in computer logic but also describes the data in terms the computer can virtually 'understand' -the model sets up its version of the real world with all its rules and orders that your data must follow" (Tomlinson, 2011, p. 97).

As a requirement for this project, the system used Esri's ArcGIS Desktop as the underlying GIS software to store, maintain, and visualize the data. The project team 
therefore had three options for databases: ArcSDE Geodatabase, File Geodatabase, and Personal Geodatabase. ArcSDE Geodatabase was eliminated because the requirements of the system did not require multi editing of data; also ArcSDE Geodatabase needs an underlying Relational Database Management System (RDBMS) -such as Oracle database software or IBM's DB2 - that can overwhelm the museum's cost and maintenance potentials. Another reason for the elimination was the museum's network limitation, which forced the system architect to keep the database locally on the system's machine. A comparison between File Geodatabase and Personal Geodatabase was then conducted to choose the most suitable option for the system, as shown in Table 4-1.

Table 4-1: File and Personal Geodatabase Comparison Summary

\begin{tabular}{|c|c|c|}
\hline Criteria & File Geodatabase & Personal Geodatabase \\
\hline Operating System & Cross-Platform & Windows \\
\hline Size & Limited to disk space & $2 \mathrm{~TB}$ \\
\hline Scalability & Small and large datasets & Small datasets \\
\hline Performance & Faster & Slower \\
\hline Notes & File Geodatabases use one third of the same spatial data \\
& \multicolumn{2}{|c|}{ store in Personal Geodatabase (Esri, 2010) } \\
\hline
\end{tabular}

A File Geodatabase is stored as an operating system's binary files, which store and manage spatial and attribute data. Hence, it is platform independent, which means it can work on both Windows and UNIX operating systems. The Geodatabase size is limited to the available disk space; it is suitable for small and large datasets. It "provides excellent performance and scalability, for example, to support individual datasets 
containing well over 300 million features and datasets that can scale beyond $500 \mathrm{~GB}$ per file with very fast performance" (Esri, 2010). This property was extremely valuable since the system database size was expected to increase as a result of adding new geological areas to the tour in the future. Meanwhile, a Personal Geodatabase stores and manages spatial and attribute data in a single Microsoft Access file; therefore, it can run only on Windows operating systems, which satisfies the system requirements. However, the limitation of the database size is to two terabytes (TB). After the database reaches 250 Megabytes (MB) its performance gradually slows down (Esri, Types of Geodatabases, 2010). Thus, a File Geodatabase was the suitable option for the system.

The system database was built to be used by Esri's ArcGlobe 9.3.1 to visualize the tour's geological areas as three-dimensional features. The implementation of the data model is shown in Figure 4-2.

\begin{tabular}{|c|c|}
\hline Name & Type \\
\hline TुBFB & File Geodatabase Feature Dataset \\
\hline क्रSBC_StreetNet & File Geodatabase Feature Dataset \\
\hline 装Anno_31_32 & File Geodatabase Relationship Class \\
\hline 爾BFBObserver1Shed & File Geodatabase Raster Dataset \\
\hline 爾 BFBObserver2Shed & File Geodatabase Raster Dataset \\
\hline BFBObserver3Shed & File Geodatabase Raster Dataset \\
\hline$\because$ TourStops & File Geodatabase Feature Class \\
\hline A TourStopsAnno & File Geodatabase Feature Class \\
\hline
\end{tabular}

\section{Figure 4-2: The System Geodatabase Contents}

The database had a feature class to keep the locations and information of all the incorporated geological areas in the Multi-touch GIS-based Tour of San Bernardino Geological Wonders. Each geological area was represented by a feature dataset containing the required feature classes to visualize the area, as explained in the 
conceptual model. Figure 4-3 shows an example of the contents of a geological area feature dataset.

\begin{tabular}{|c|c|}
\hline Name & Type \\
\hline 哭Anno_18_43 & File Geodatabase Relationship Class \\
\hline 哭Anno_19_42 & File Geodatabase Relationship Class \\
\hline 钴Anno_20_41 & File Geodatabase Relationship Class \\
\hline 哭Anno_37_40 & File Geodatabase Relationship Class \\
\hline$\because$ BFBObserver1 & File Geodatabase Feature Class \\
\hline$\because$ BFBObserver2 & File Geodatabase Feature Class \\
\hline$\because$ BFBObserver3 & File Geodatabase Feature Class \\
\hline I Contour150M_SL100 & File Geodatabase Feature Class \\
\hline A Contour150M_SL100Anno & File Geodatabase Feature Class \\
\hline A Observer1Anno & File Geodatabase Feature Class \\
\hline A Observer2Anno & File Geodatabase Feature Class \\
\hline A Observer3Anno & File Geodatabase Feature Class \\
\hline I I SBCM_TO_BFB & File Geodatabase Feature Class \\
\hline
\end{tabular}

Figure 4-3: Example of a Feature Dataset that Represent a Geological Area

The feature dataset had two line feature classes, one to represent the route from SBCM to the geological area and another to represent the contour lines for the area. It also had two or more point feature classes acting as inputs for the viewshed analyses. The results of the analyses were raster datasets stored outside the feature dataset because of the restriction on storing a raster dataset in a feature dataset. The database's feature classes had corresponding feature annotation classes to be used in labeling the features due to limitations in ArcGlobe direct feature class labeling. For example, the labeling engine does not follow the layer's label settings, as shown in Figure 4-4. The San Bernardino County street network dataset was used only for generating routes from the museum to each of the participating geological area. Including a geological area in the tour outside the region of San Bernardino will require adding a broader street network 
covering that area. The database was structured to allow adding new geological areas to the tour easily, as requested by the client.

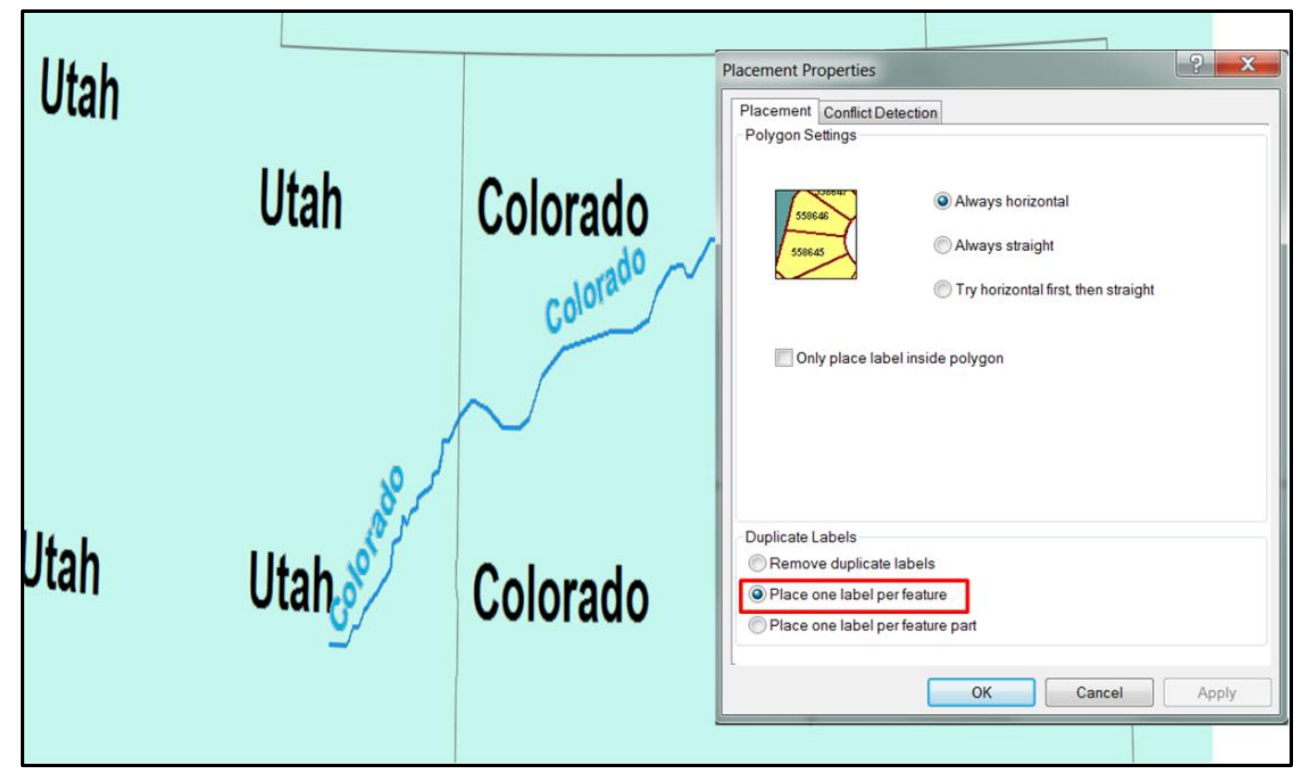

Figure 4-4: Some Features Labeled in ArcGlobe

Several attributes were stored in each Feature Class in the database. Table 4-2 list the main database attributes. 
Table 4-2: The Database Feature Classes and Main Attributes

\begin{tabular}{|c|c|c|c|l|}
\hline Feature Class Name & Geometry & Main Attributes & Data Type & \multicolumn{1}{|c|}{ Notes } \\
\hline \multirow{2}{*}{ Observer1 } & \multirow{2}{*}{ Point } & Name & Text & $\begin{array}{l}\text { It is the name of an } \\
\text { observer. }\end{array}$ \\
\cline { 3 - 5 } & & ID & Integer & $\begin{array}{l}\text { It is a unique ID to } \\
\text { distinguish an observer. }\end{array}$ \\
\cline { 3 - 5 } & & OFFSETA & Double & It is the height of an \\
observer.
\end{tabular}

In addition to the database, the system used a map service of the world from Esri's map services as a basemap. The map was draped on a 10-meter resolution DEM stored in the system hardware to create the terrain surface, which represented the tour's geological areas. The system also used media files such as video and pictures that were stored in the system's directory. 


\subsection{Data Sources}

The Information Services Department of San Bernardino County (ISD) was the main provider of the system data. They provided a 10-meter resolution DEM and the street network dataset for San Bernardino County. The GIS data were projected as a State Plane projection using the datum North American Datum 1983. All the other data in the

database were generated from them. The incorporated media files were prepared and provided by SBCM. Table 4-3 shows detailed information of the data. 
Table 4-3: List of the System Data Sources

\begin{tabular}{|l|l|l|}
\hline Feature Class/Raster & The Usage & Source \\
\hline ClaurStops Point Feature & $\begin{array}{l}\text { It stored the geological areas location } \\
\text { information. }\end{array}$ & $\begin{array}{l}\text { The Project } \\
\text { Team }\end{array}$ \\
\hline Observer Point Feature & $\begin{array}{l}\text { It could be two or more classes per } \\
\text { geological area. It was used as input to } \\
\text { generate viewshed analysis. }\end{array}$ & $\begin{array}{l}\text { The Project } \\
\text { Team }\end{array}$ \\
\hline File & $\begin{array}{l}\text { It is the result of performing viewshed } \\
\text { analysis. }\end{array}$ & The Project \\
Team
\end{tabular}




\subsection{Data Scrubbing and Loading}

ISD provided the San Bernardino County street network dataset in a file geodatabase version 10. However, the museum's system used ArcGIS Desktop 9.3.1 because of the requirements of TouchShare GIS 6.2 software. A downgrading process for the dataset was needed. The dataset holds two feature classes: street network and intersection junctions. It also stores the file network dataset. Several steps were involved in the process. In ArcGIS 10, a new file geodatabase, 9.3 version, was created using the Create File GDB tool. ISD's dataset feature classes were exported to the created file geodatabase. The geodatabase was then moved to ArcGIS 9.3 and a new feature dataset was created to hold the feature classes. Inside the feature dataset, a new file network dataset was created that had the same parameters as the original ISD's network dataset. Figure 4-5 shows the flow of changing the dataset from ArcGIS Desktop 10 to 9.3.

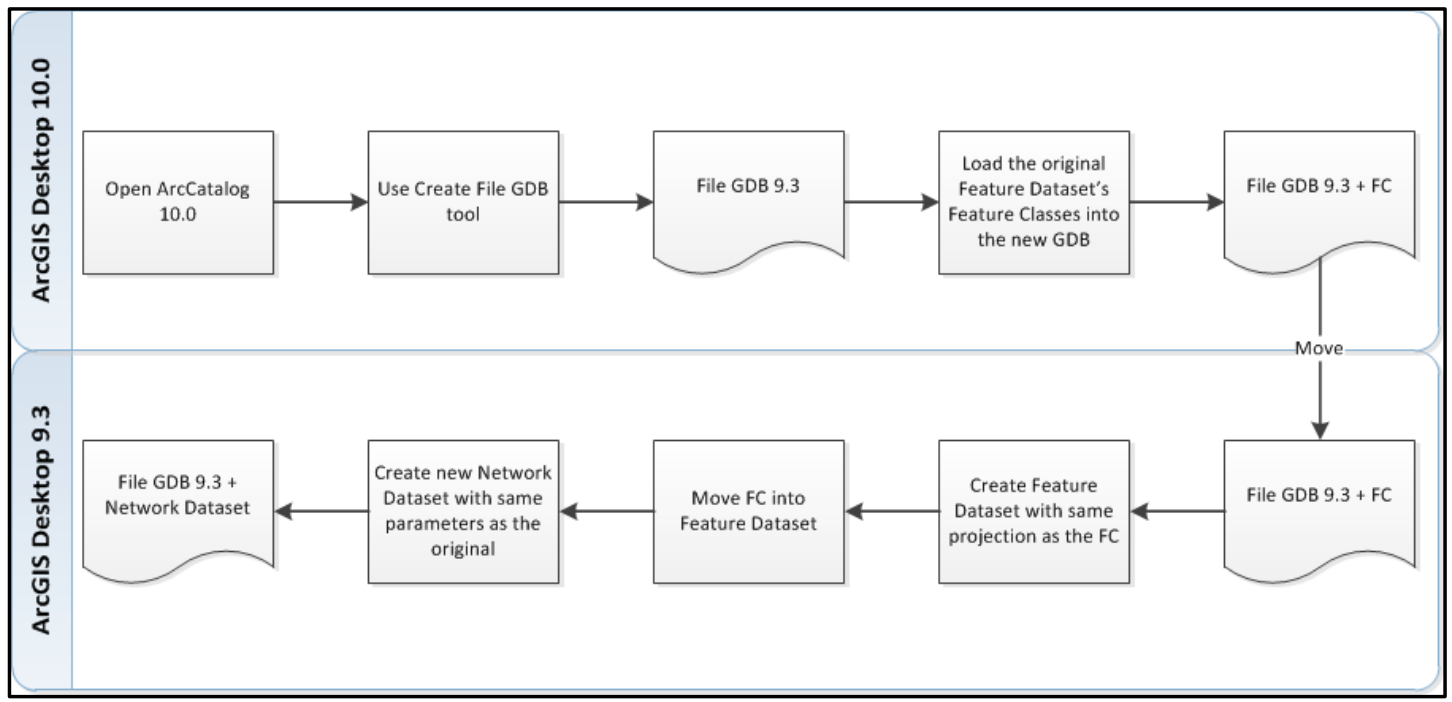

Figure 4-5: The Process of Converting the Network Dataset from ArcGIS Desktop 10.0 to 9.3 
In addition to the downgrading process, ISD provided the data in a State Plane projection, which is a Projected Coordinate System (PCS). However, Esri recommended the use of a Geographic Coordinates System (GCS) for ArcGlobe document's spatial data that fall between the coordinates $45^{\circ} \mathrm{N}$ and $45^{\circ} \mathrm{S}$ latitudes. It enhances the performance of the ArcGlobe document because GCS datasets "have the benefit of having pyramids that are specifically conformant to ArcGlobe software's cell size requirement, which avoids further resampling operations" (Esri, July 2004). Thus, the system DEM and San Bernardino County street network dataset projections were transformed to the GCS WGS 1984 projection using the Project tool in ArcToolbox.

\subsection{Summary}

The system database worked as a container for the system data. It helps the system to meet all the functional requirements. There were several steps to build the system's database. A conceptual model was built based on the client's requirements. The system entities, attributes, and relations were defined to create the conceptual model diagram using UML. Next, the diagram was transformed into the logical model of the database. The transformation process created the database feature datasets, feature classes, and attributes. There were three options for the database type: ArcSDE, File, and Personal Geodatabase. File Geodatabase was the most suitable option for the system due to its scalability and performance. The main GIS data provider for this project was ISD. The data were used to generate the rest of the system GIS data. Before loading the data in the database, several processes were performed, such as re-projecting the data and downgrading them to the compatible ArcGIS Desktop version. SBCM provided the 
media files, which were incorporated into the tour. The next chapter discusses the steps needed to build the system. 



\section{Chapter 5 - Implementation}

After the project database had been prepared, the project implementation was initiated. This chapter discusses the steps used to develop the final solution that addressed all of the client's requirements. It explains how and why each step was performed, and what the output was used for. The implementation of the project involved preparing the development environment, generating contour lines, performing viewshed analysis, and creating a route from each geological area to the San Bernardino County Museum.

\subsection{Prepare the Development Environment}

The first step in the development of the Multi-touch GIS-based Tour of San Bernardino Geological Wonders was to prepare the development environment. The system was created in the University of Redlands development environment, and was then moved to a replica environment at the museum. The system uses a TouchTable (from TouchTable Inc.) as the display medium and input-and-output device. In order for the TouchTable to be used within the development environment, two software packages needed to be installed: TouchDrive 5.1 and TouchShare GIS 6.2. TouchDrive 5.1 acts as a translator of touch gestures on the device surface to the system's operating system. TouchShare GIS 6.2 is the user interface for the system. Both run on a personal computer (PC) with a Windows 7 operating system. After the installation, the TouchTable needed to be calibrated using TouchDrive software, as shown in Figure 5-1. The TouchShare GIS is not true GIS software. Rather, it is an interface for Esri's ArcGlobe (the threedimensional GIS software). Thus, ArcGIS Desktop 9.3.1 was installed with 3D Analyst 
Extension on the PC. ArcGIS Desktop 9.3.1 was installed because it was the latest version supported by TouchShare GIS 6.2.

All of the required software for SBCM's system is listed in Table 5-1. The development environment was in the University of Redlands Master of Science in Geographic Information System program. All of the software and hardware belonged to the university.

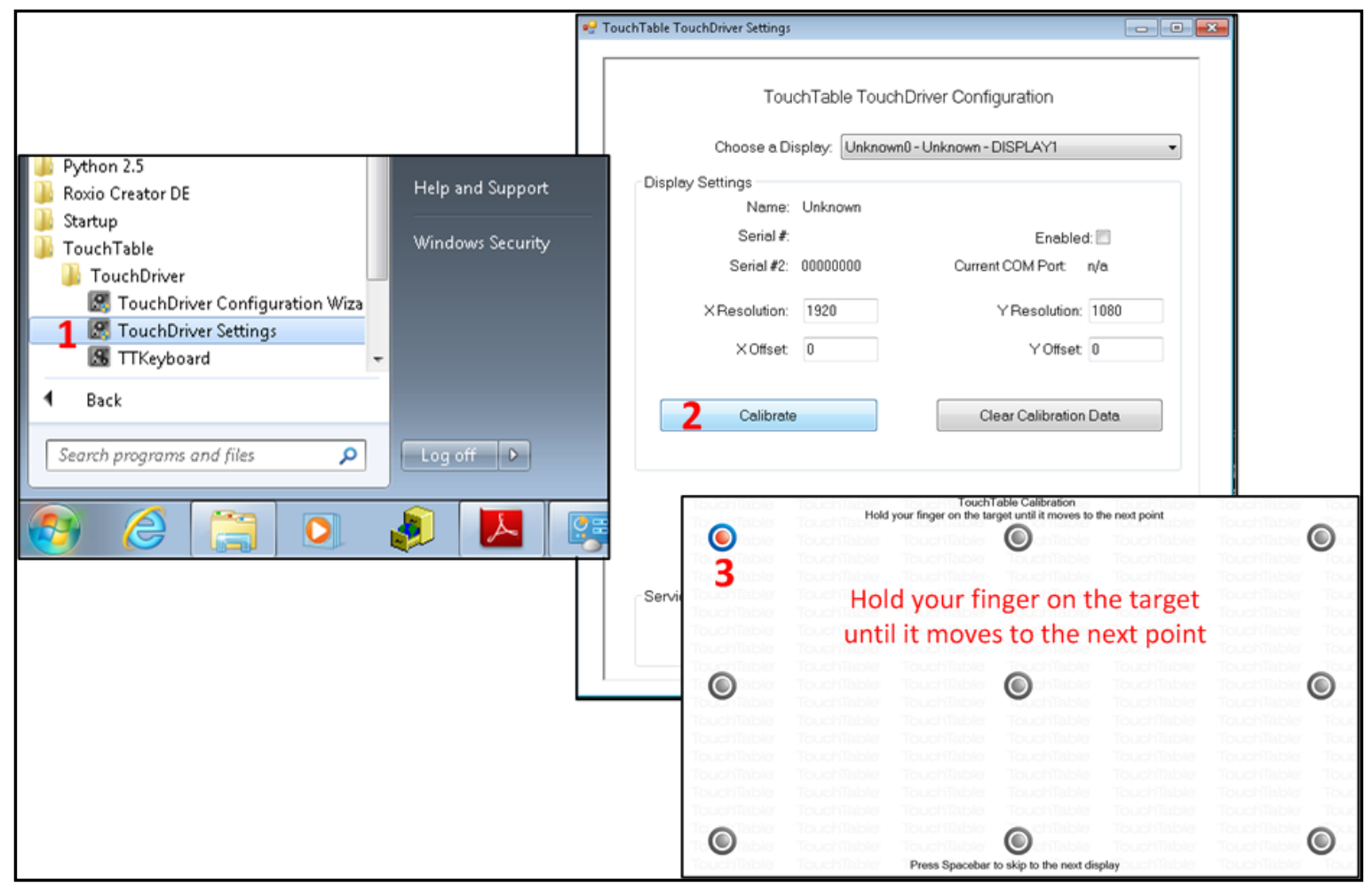

Figure 5-1: TouchTable Calibration Steps 
Table 5-1: The Required Software for The System

\begin{tabular}{|c|c|c|}
\hline Software Usage & Software Name & Version \\
\hline Operating System & Windows 7 & - \\
\hline Windows Framework & Windows Framework 4.0 & 4.0 \\
\hline \multirow{2}{*}{ TouchTable } & TouchDrive & 5.2 \\
\cline { 2 - 3 } & TouchShare GIS & 6.2 \\
\hline \multirow{2}{*}{ GIS Software } & ArcGIS Desktop & \\
& 3D Analyst extension and & 9.3 .1 \\
& Network Analyst extension & \\
\hline
\end{tabular}

\subsection{Prepare The Geological Areas}

The system consists of a tour of several geological areas. Each area needed to be prepared separately to be included in the system. The preparation process involved creating contour lines, generating two or more viewshed raster datasets, generating a route from SBCM to the area, and incorporating related media files.

\subsubsection{Create Contour Lines}

Contour lines are lines that pass through points with equal elevation. The system used them to enhance the visualization and understanding of the geological areas' terrain. In order to build the contour lines, an elevation source, such as a digital elevation model (DEM) or triangulated irregular network (TIN) was needed. The system's contour lines generated using the DEM provided by the Information Service Department of San Bernardino County (ISD). The contour lines were used by ArcGlobe software. As more 
features were added to the ArcGlobe document, rendering time increased, and software performance was impacted. As a result, the contour lines were re-generated only to cover the extent of each of the geological areas of the tour.

The contour lines were created in several steps, using ArcGIS Desktop software. First, in ArcMap, the extent of a selected geological area was specified by creating a new polygon Feature Class to store the extent. Then, the system's DEM was clipped using the Clip tool from the Data Management toolbox to produce a new DEM that covered only the area of interest. To produce the contour lines, the clipped DEM was used as the input for the Contour tool, as shown in Figure 5-2. The Contour interval-the elevation distance between contour lines - was specified depending on the topographical nature of the geological area; whenever a surface had significant relief, the contour interval value was large.

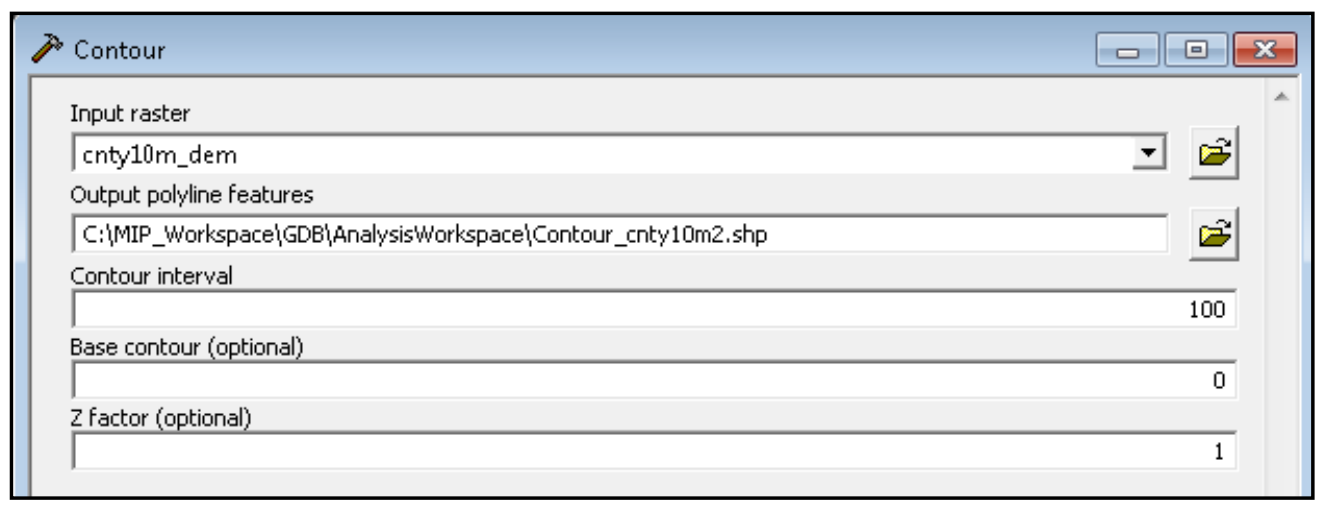

\section{Figure 5-2: Contour Tool}

After the creation of the contour lines, a line simplification process was used to reduce the point features that constructed the lines, while the main shape of the lines was maintained. The Simplify Line tool was used to generate the simplified contour lines. The tool produced two outputs: the simplified lines in a line feature class, and closed lines that collapsed to zero length because of the simplification process in a point feature class. 
The tool provided two simplification algorithms: point remove and bend simplify. The point remove algorithm reduces point features of a line by removing redundant points, but the shape of the resulting line can be distorted. The bend algorithm takes more time than the latter and applies a different technique. It finds bends across a line and removes insignificant ones, which keeps the main shape of the line intact (Esri, ArcGIS Desktop 9.3 Help, 2010). Figure 5-3 illustrates the difference between the algorithms. The bend simplify algorithm was the suitable simplification algorithm for the system. As shown in Figure 5-4, the tool accepted four inputs: input line feature class, output feature class location, simplification algorithm, and tolerance length of the reference bend baseline and its linear unit. The last step necessary to create the contour lines was to generate an annotation feature class using the lines elevation value. This was used to label the lines in ArcGlobe. The process to create contour lines was repeated for each area of the tour.

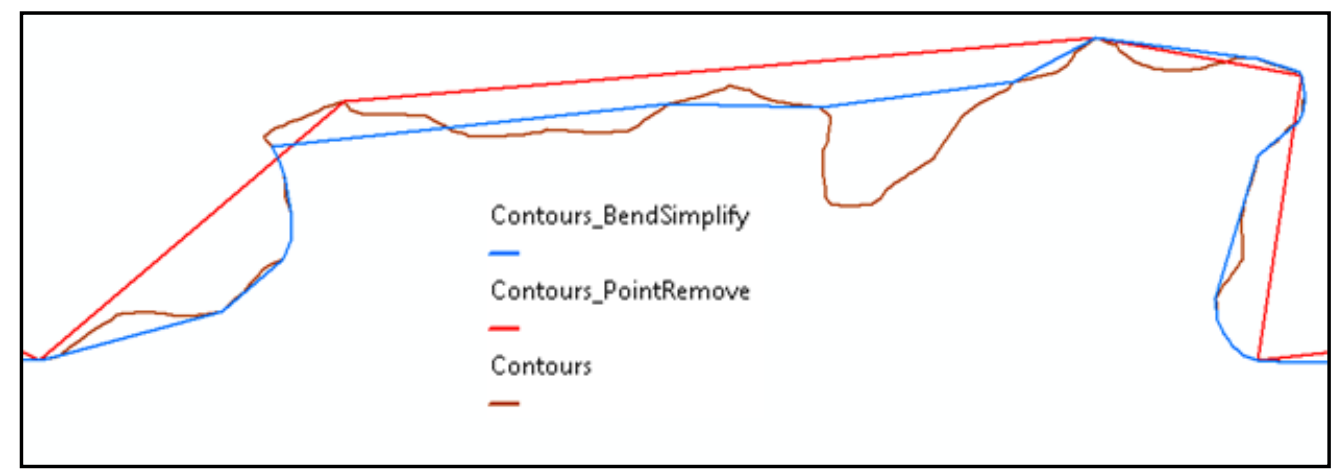

Figure 5-3: Comparison Between the Simplification Algorithms 


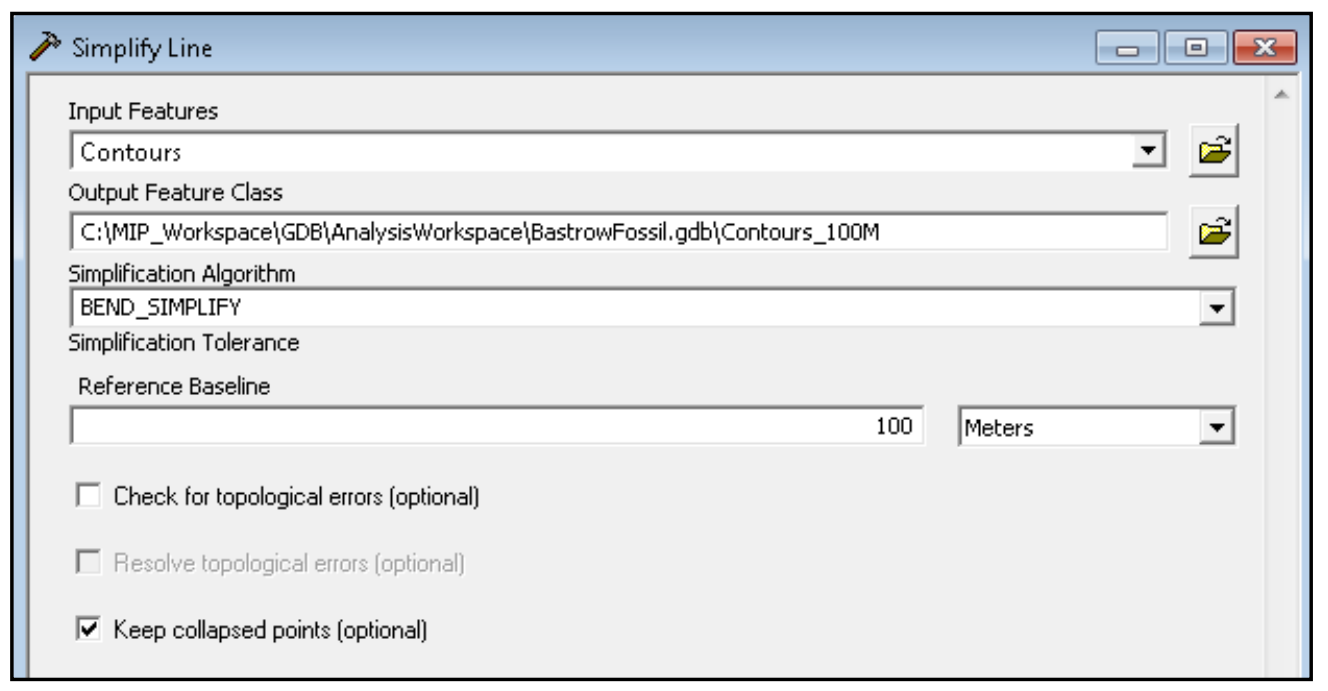

\section{Figure 5-4: Simplify Line Tool}

\subsubsection{Create Viewshed Analysis}

Viewshed analysis, or area visibility analysis, is a common GIS function that determines the visibility of an area from one or more viewing points. "The visible area is determined by defining one location as the viewing point and then calculating the line-of-sight to every other point within the area of interest (the target points)" (Fisher, 1996, pp. 12971302). This system used viewshed analysis to allow the system's users to investigate the topographical nature of a geological area's terrain. The system allows users to pan and zoom to an area's different viewshed analysis results in order to compare them from different points of view. Each geological area can have two or more observer points, depending on the width of the area. The locations of observer points were chosen to cover different areas from different elevations within the extent of a geological area. An observer point can have nine different parameters that are used to control viewshed analysis. The parameters manipulate various characteristics of the analysis, such as the 
height of the observer, the horizontal and the vertical angle of visibility, and the search distance. Figure 5-5 illustrates those parameters. The system used only one parameter, which was the height of the observer. This parameter provides the perspective of a standing person who is looking around the area. Each point had its own viewshed result. The viewshed result was a binary raster dataset. The zero-valued cells were invisible cells from an observer point and the one-valued cells were visible cells. The elevation source used to perform the analysis was a 10-meter resolution DEM that was clipped to cover a geological area extent.

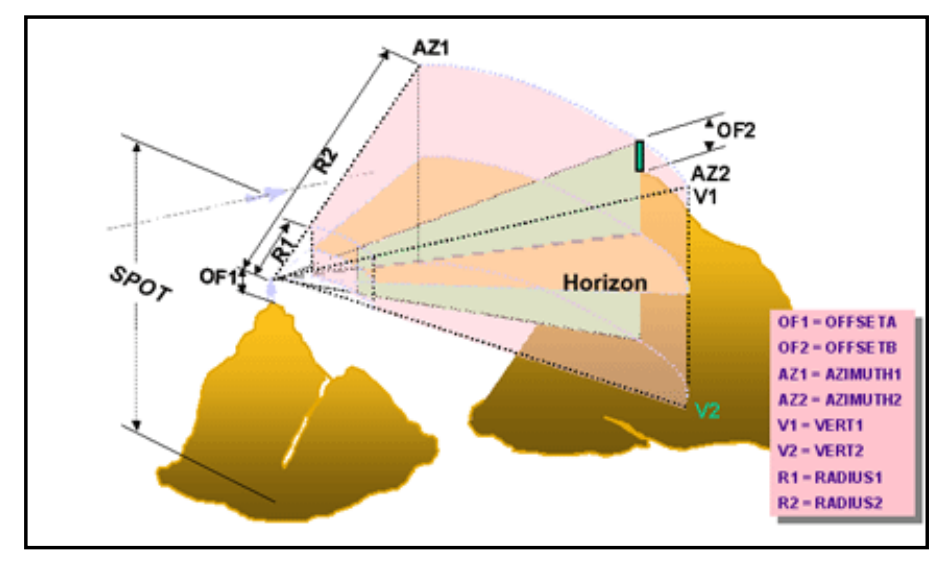

\section{Figure 5-5: Viewshed Analysis Parameters}

Performing the analysis involved several steps. First, a point feature class that represents an observer point was created. Using ArcMap, the location of the points were determined and stored. Then a new field was created in the feature class with name "OFFSETA". This was used to store the height of the observer, which was set to 1.8 meters. The name of the field was a predetermined, case-sensitive word. The height and the elevation from the DEM were added together by the software to be used in the analysis. The analysis was carried out by using the Viewshed tool from 3D Analyst 
toolbox. The tool required three mandatory inputs and three optional inputs, as shown in Figure 5-6.

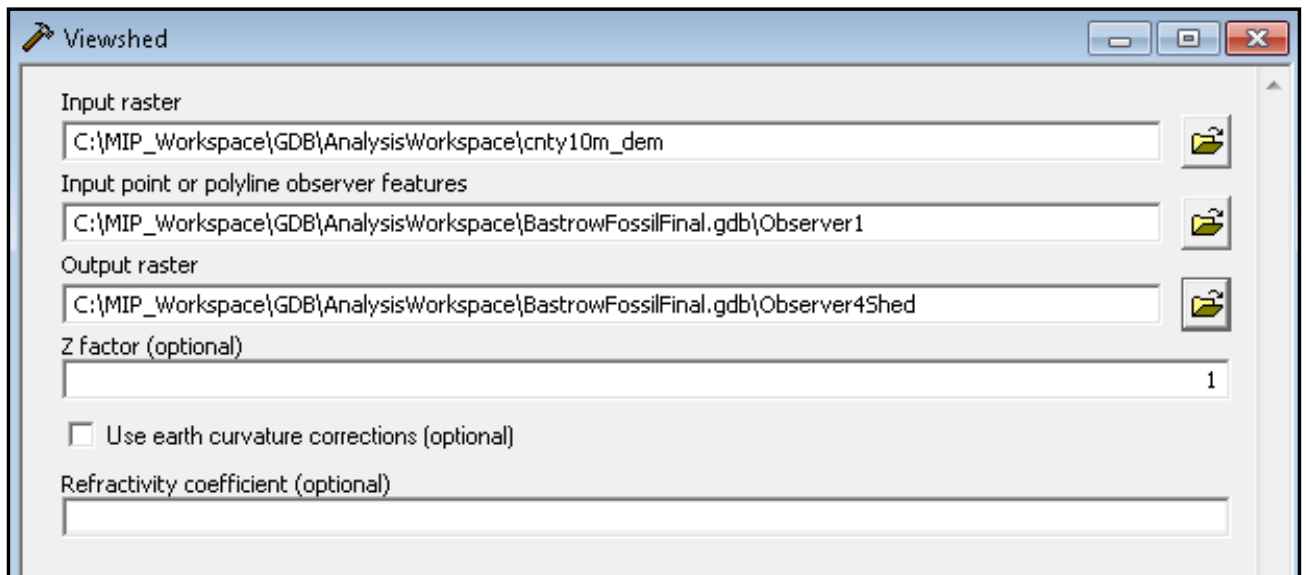

\section{Figure 5-6: The Viewshed Tool}

The first input was the elevation source; the tool used a DEM clipped to the extent of the geological area of interest. The tool also used the created point Feature Class as the Observer Feature input, and the output location of the result of the analysis was specified in the system database. The other three optional inputs were Z-Factor, Curvature Correction, and Refractivity Coefficient. The Z-Factor was used to adjust the difference of unit measurement between ground unit and elevation unit, if any. The system was using meters as the unit of measurement for both, so the value was set to one, indicating that there was no difference. The Curvature Correction option determined whether to consider the Earth's curvature or not. The Earth's curvature was neglected because the area of interest was small. Meanwhile, The Refractivity Coefficient was a coefficient of refraction of visible light in the air; the default value $(0.13)$ was used. This process was repeated for each observer point in each geological area of the tour. 


\subsubsection{Create the Routes to the Museum}

One of the requirements for the system requirements was for it to find the shortest routes from the museum to each geological area. The requirement was included to encourage the system's users to visit the areas by suggesting the shortest route. GIS provides the mechanism to generate such a route utilizing the network analysis capabilities. The system used the Network Analyst extension in ArcMap to solve the route between the museum and each of the tour's stops, separately. It also used the Street Network Dataset of San Bernardino County as the solver's network, and loaded the point TourStops Feature Class as the tour's stops. Figure 5-7 illustrates the solving of a route. The generated routes represent the shortest paths between two points.

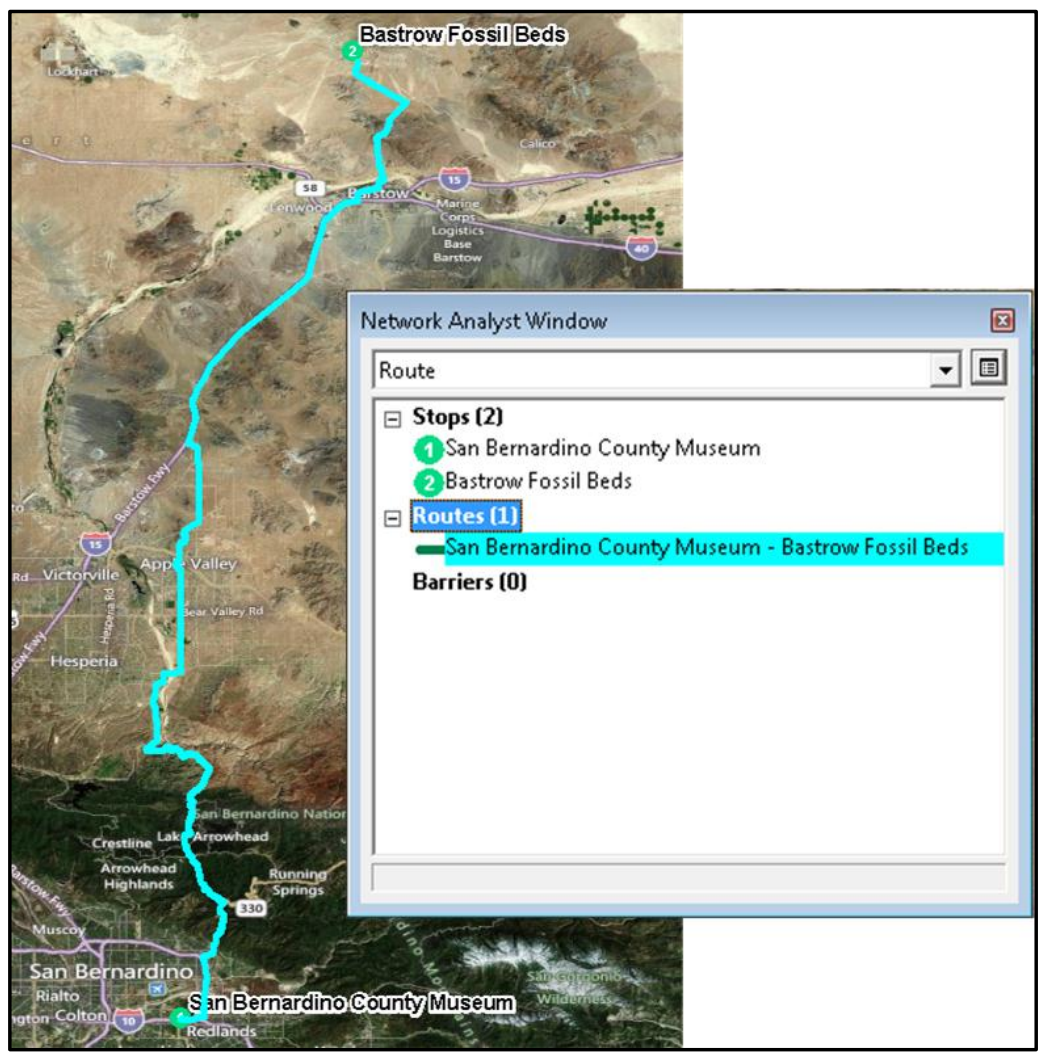

Figure 5-7: Network Analysis in ArcMap 
After downgrading the street network dataset and re-projecting its Feature Classes as explained in Chapter Four, it was loaded into ArcMap with the TourStops Feature Class. Then, using the Network Analyst toolbar, a new route was generated for each geological area. The generated route was exported to each geological area's feature dataset.

\subsubsection{Incorporating the Tour's Media Files}

Presenting a video and slides interactively about each of the tour's geological area was a critical requirement of the system. This would allow the users to acquire more information and knowledge about the areas. The museum prepared many media files for each area that could not be handled by the File Geodatabase, and ArcGlobe was incapable of viewing them properly. Additionally, TouchShare GIS opened the media files using the default operating system software, which was not designed as a touch application. As a result, an external media player that could be used to view those files

was necessary. Though there were different types of media files, the player would need to view them in a single interface for usability reasons. Moreover, the player would need to allow the system administrators to update and add the media file easily and as needed. These criteria influenced the development of the Tour's Media Player.

The museum wanted to use Windows Presentation Foundation (WPF) to develop the player in order to utilize the interactivity this technology provides. As a result, Visual Studio 2010 was used as integrated development environment (IDE) to develop the player. WPF 4.0 was used to build the user interface and VB.NET was the programming language used to develop the player functionalities. The media player consists of three tabs: Welcome, Video, and Slides. The Welcome tab was developed to provide a 
welcome statement for the users and to explain how to use the system. The Video tab allowed the users to play and navigate through a video about the tour's geological area. The Slides tab was developed to navigate through a geological area's slides either manually by touching the next and previous buttons, or automatically by touching the slideshow start button. Figure 5-8 shows the three tabs.

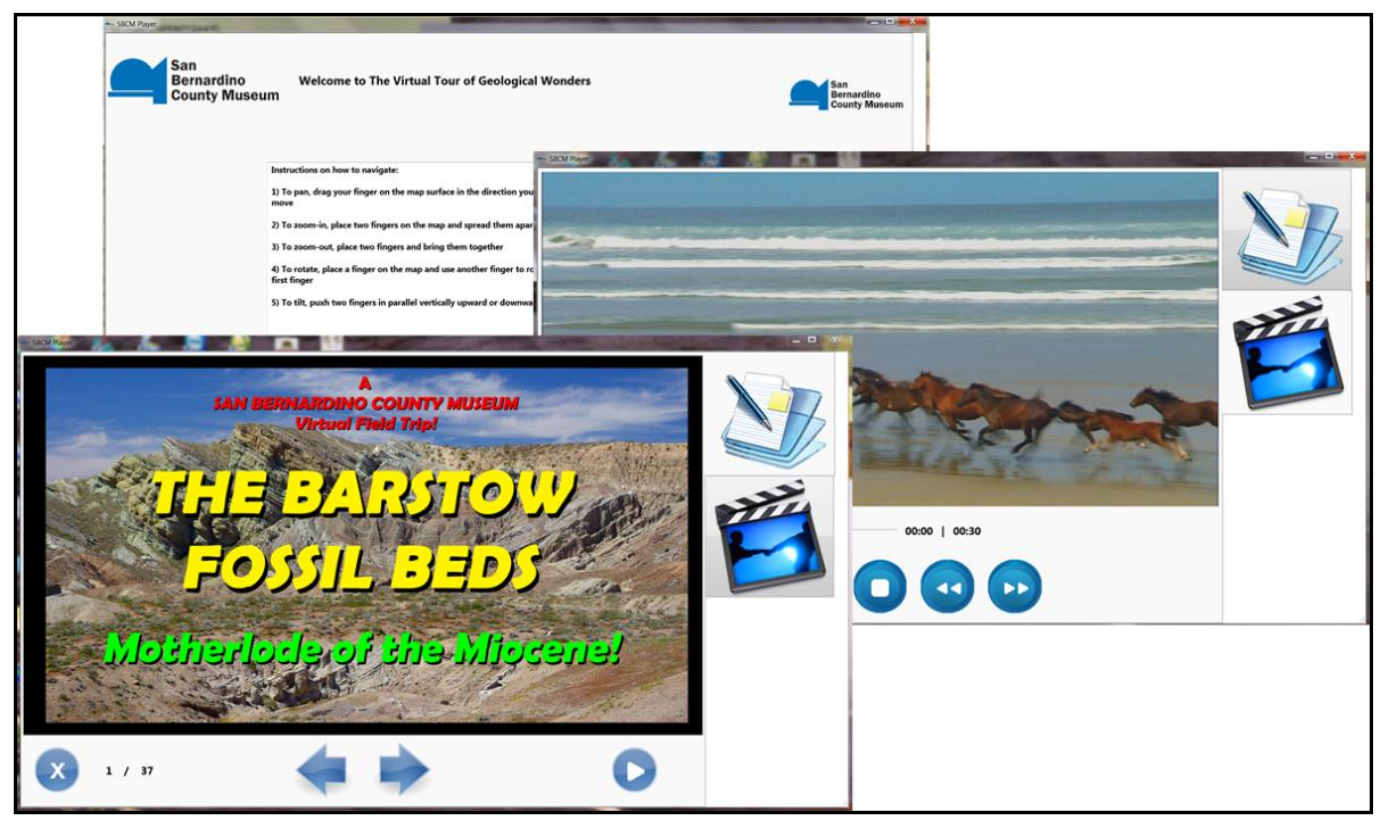

Figure 5-8: The Tour's Media Player

The player is automated to start when the tour stops at a geological area, and the player only displays the media files corresponding to that area. In addition, to increase usability, if a geological area only has slides (not a video), then only the Slides tab will display. Updating the media files for a tour is a simple task. The media files are stored on the operating system's directory, which can be replaced or added easily. The player can view the updated files without needing to recompile and reinstall the player. If a new geological area needs to be added, the media player can view the new tour's content by adding a reference to the folder's directory in the player's configuration file. There is no 
need to open the player's source code to add the references, then recompile and install it again. It is direct and easy as requested by the museum. See Appendix A for the details on how to add new media files to the tour. At the end, an installation package was created to install the player at the client's environment.

\subsubsection{Preparing the ArcGlobe Document}

ArcGlobe was the GIS software for the system. All of the prepared spatial data were loaded into an ArcGlobe document to view them in the three-dimensional environment. It used ISD's 10-meter resolution DEM as the elevation layer. ArcGlobe's default, highresolution, satellite image map service from Esri was used as a basemap. The geological areas' contour lines were draped on the DEM, and were labeled using its corresponding Annotation Feature Class as 3D label. The observer point Feature Classes were loaded as 3D symbol features. In addition, a group layer was used to group viewshed results for each geological area to view them in sequence. This is further explained in the next section. The routes from the museum were also added to the document. The Annotation Feature Classes were loaded and their elevation was increased with a constant value to make them more noticeable for the system's users, as shown in Figure 5-9. The elevation increment also helped to prevent the text being hidden behind high-elevation features. A scale range was set for each layer to enhance the performance of the document. For each geological area location, a bookmark was created to be used as a stop in the tour. 


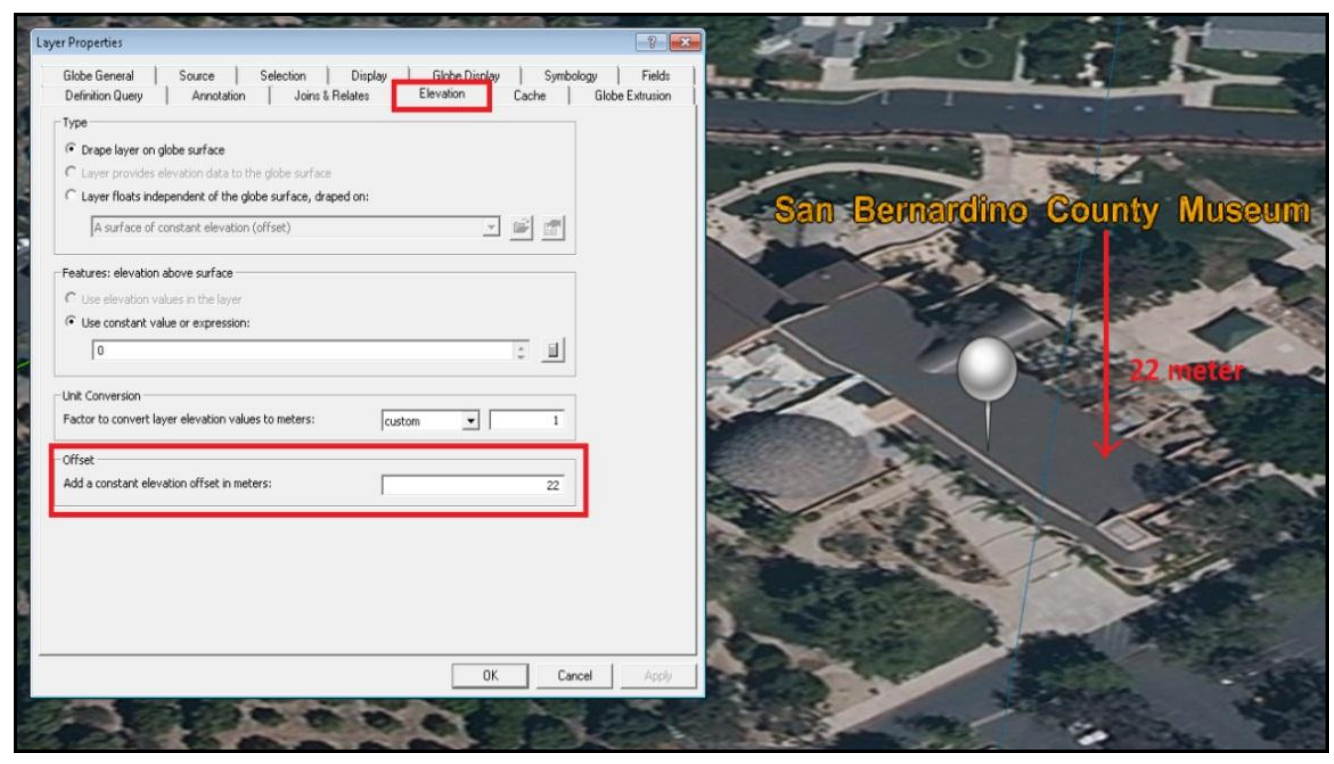

\section{Figure 5-9: Setting Constant Elevation for the Annotation Feature}

\subsubsection{Create the Museum's Tour}

The tour was created using TouchShare GIS software, which acted as the user interface for the system. The software was connected to the prepared ArcGlobe document to display its content in a new interface. The interface was developed to detect certain hand gestures on the TouchTable surface and translate them to an action, such as zoom, pan, and tilt.

After the connection had been made with the document, the software provided a menu to create the tour. Figure 5-10 shows the tour's Settings menu. 


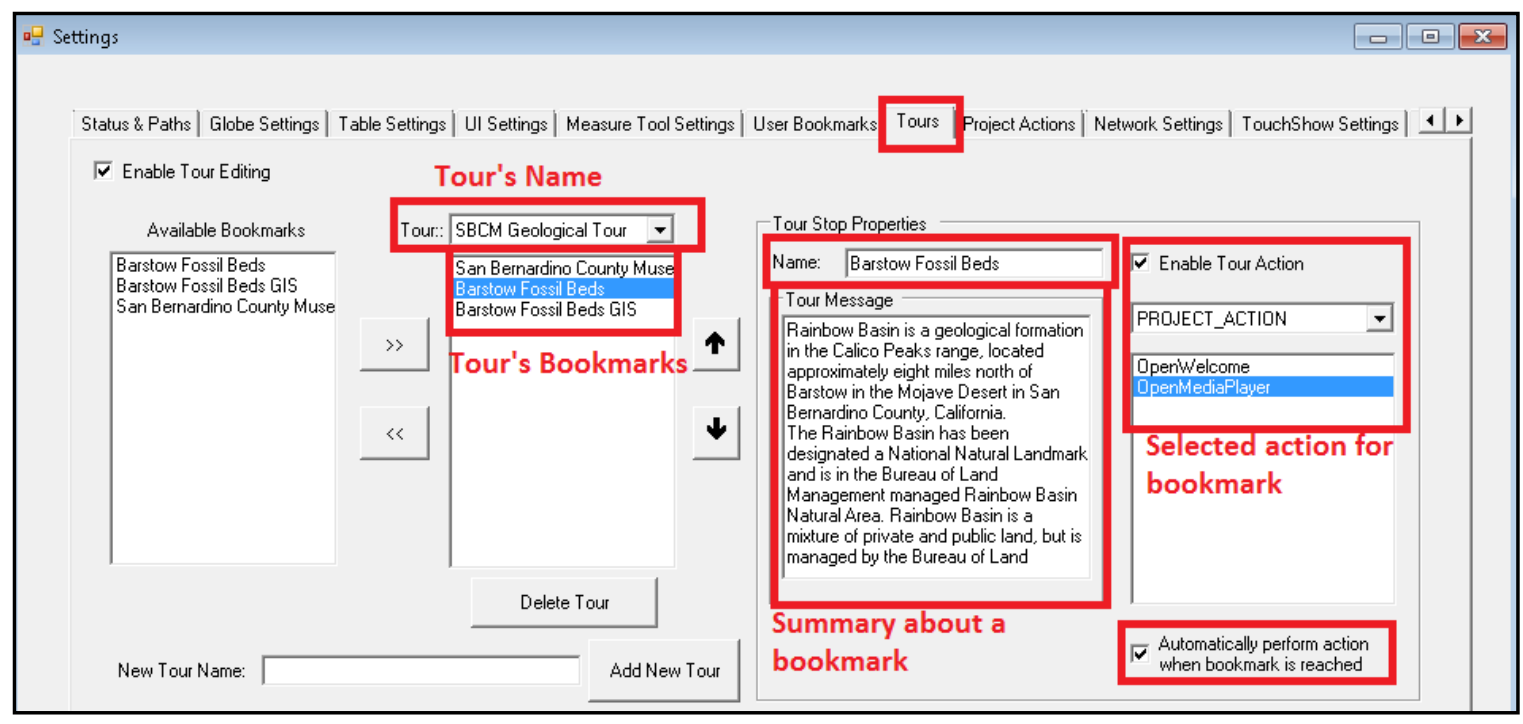

Figure 5-10: The Tour's Settings

First, the tour's name was specified. Then the tour's geological areas bookmarks, which were determined in the ArcGlobe document, were added in sequence. The sequence reflected the order of the geological area in the tour. Next, a summary about each area was written to display when the tour reached the particular area. TouchShare GIS provides a set of actions associated with each stop on the tour. For instance, it allows users to compare the view of the system's map with or without a specified layer by swiping a finger left and right. It also provides the ability to view a set of layers in a group layer by showing one layer at a time by simply moving a scroll bar. This allows users to view the geological area's viewshed results. In addition to the predefined actions, the software allowed for creating custom actions by launching a program from the operating system. The custom action was used to call the media player. This was done by specifying the location of the player's executable file and passing the name of the geological area as specified in the player's configuration file as argument, as shown in 
Figure 5-11. Each of the tour's bookmarks can have one action; the action can be set to start automatically when the tour reaches the specified bookmark.

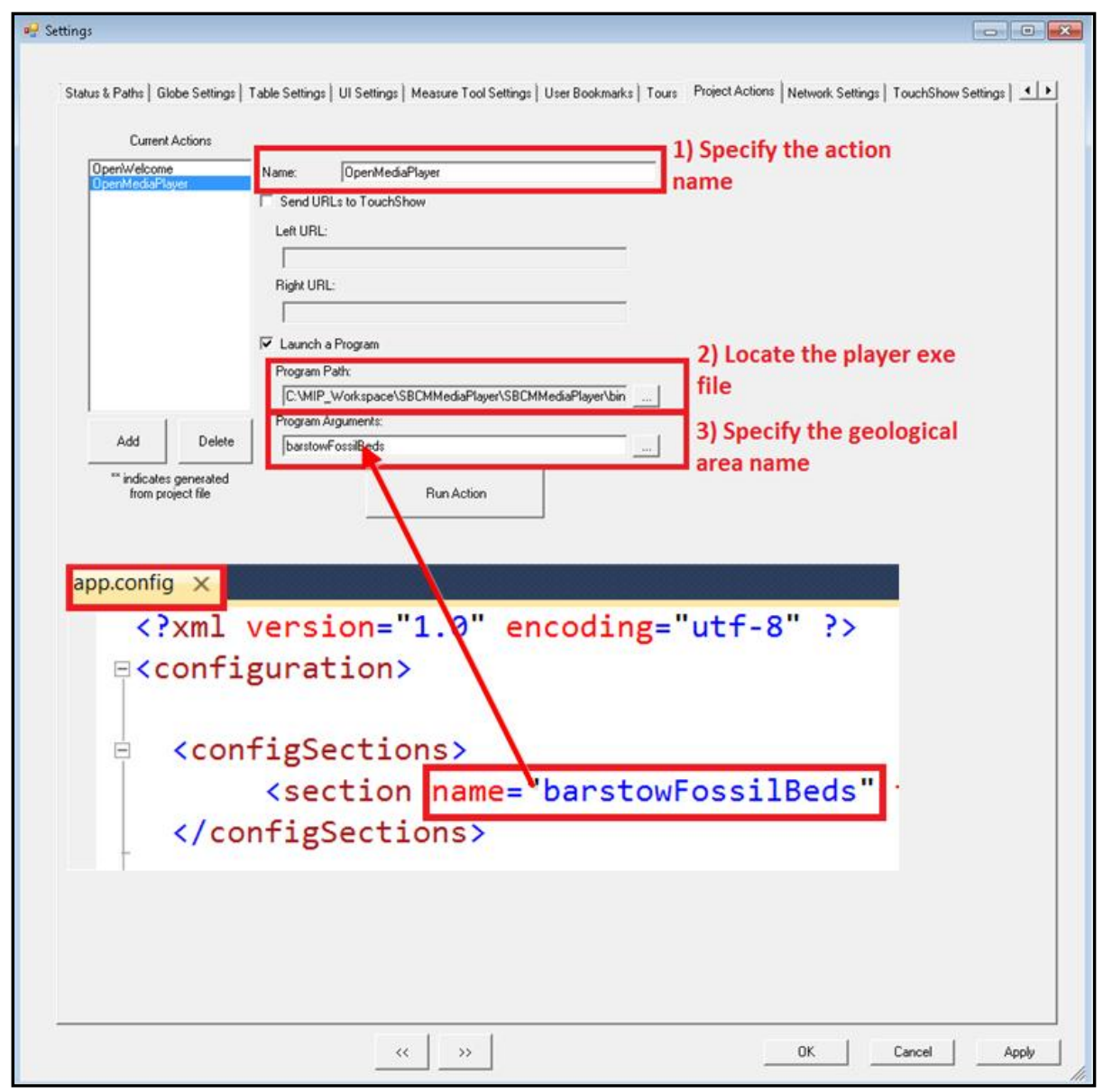

\section{Figure 5-11: Example of a Custom Action}

The tour was ready after specifying all of the previous settings. The user can start the Multi-touch GIS-based Tour of San Bernardino Geological Wonders using the Tour's Toolbar from TouchShare GIS software. It allows the system's users to navigate to the next or the previous geological area in the tour and to jump to a specific tour. It also provides the ability to launch the specified action for a geological area. 


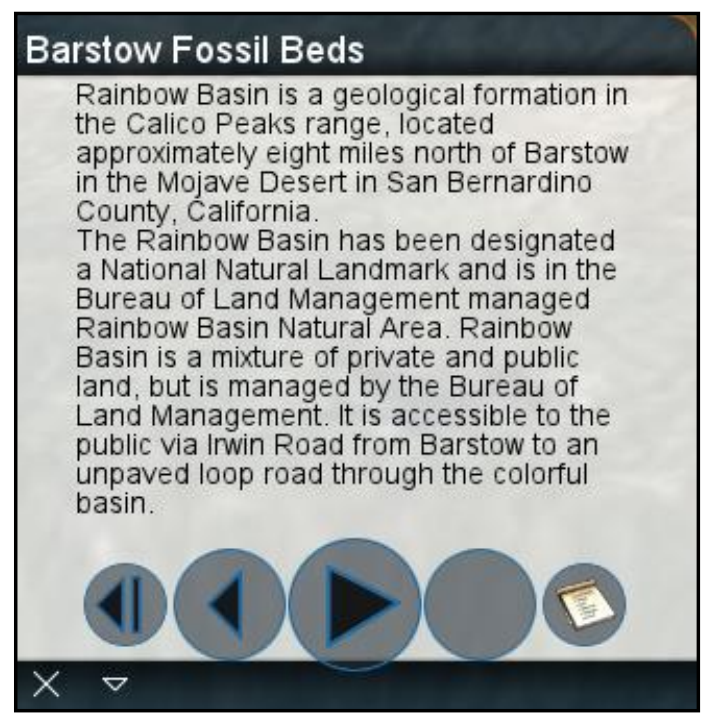

Figure 5-12: The Tour's Toolbar

\subsection{Summary}

This chapter detailed the steps involved in the development of the museum's system. It discussed the software and the hardware needed to build the development environment. Then it detailed the required processes and analyses to construct a tour of a geological area. Each geological area needed contour lines to enhance the visualization and understanding of the geological area's terrain. It also required different viewshed datasets from different observation points, which provide multiple points of view for a geological area. In addition, the system generated routes from the museum to each of the areas in the tour to encourage the users to visit the areas. After the analyses were performed, the results were draped on a 10-meter resolution DEM in an ArcGlobe document.

TouchShare GIS used the document to build the tour. In addition, it used the developed media player to incorporate the tour's media file. The next chapter focuses on the system's result. 


\section{Chapter 6 - Results and Analysis}

After the system was completed and ready to use, the deployment phase of the project was launched. The system was deployed in the client environment at the museum. Next, a demonstration was conducted to test the system, to train the museum staff on how to use and operate the system, and to gather feedback about the system functionality and performance. This chapter discusses the system's deployment phase and the results of the demonstration session.

\subsection{The System User Interface Modification}

After the system had been implemented, it was deployed at the museum in The Hall of Geological Wonders. The system's files were copied from the development environment to a portable hard drive in order to move them to the client's environment. The client's environment was different from the development environment. That led to updating ArcGIS Desktop software and TouchShare GIS software to the versions required by the system (versions are specified in Table 5-1). After the updating process, the Tour's Media Player was installed and the media files were copied to the operating system's directory. The player's configuration file was then modified to point to the directory. The last step was to copy the ArcGlobe document, TouchShare GIS file, and the system's database to the operating system. The deployment process was completed without issues and the system was ready to be demonstrated to the client. A demonstration was conducted to two curators of the San Bernardino County Museum (SBCM), and two representatives from Information Service Department of San Bernardino County (ISD). The system's full capabilities were shown to the project team. Then the client used the system for an hour by testing the system's functions and investigating the tour's 
geological stops. The client was satisfied with the tour's design and the way the media files were presented in each area. However, the client did have comments about the system's user interface (TouchShare GIS) and the system's GIS analyses. The client brought up that the software has many menus that can distract the users from starting the tour. Additionally, some menus can be invoked unintentionally by holding a finger on the TouchTable surface for more than four seconds. Those menus can open tools, such as a drawing tool; new bookmarks could unintentionally be created in the system. This would possibly misguide the users from the main purpose of the system, which is to use it for exploring and learning about the region's geological areas. The user interface also allowed the users to tamper with the tour's configuration by opening the software configuration dialog. Figure 6-1 shows some of the menus.

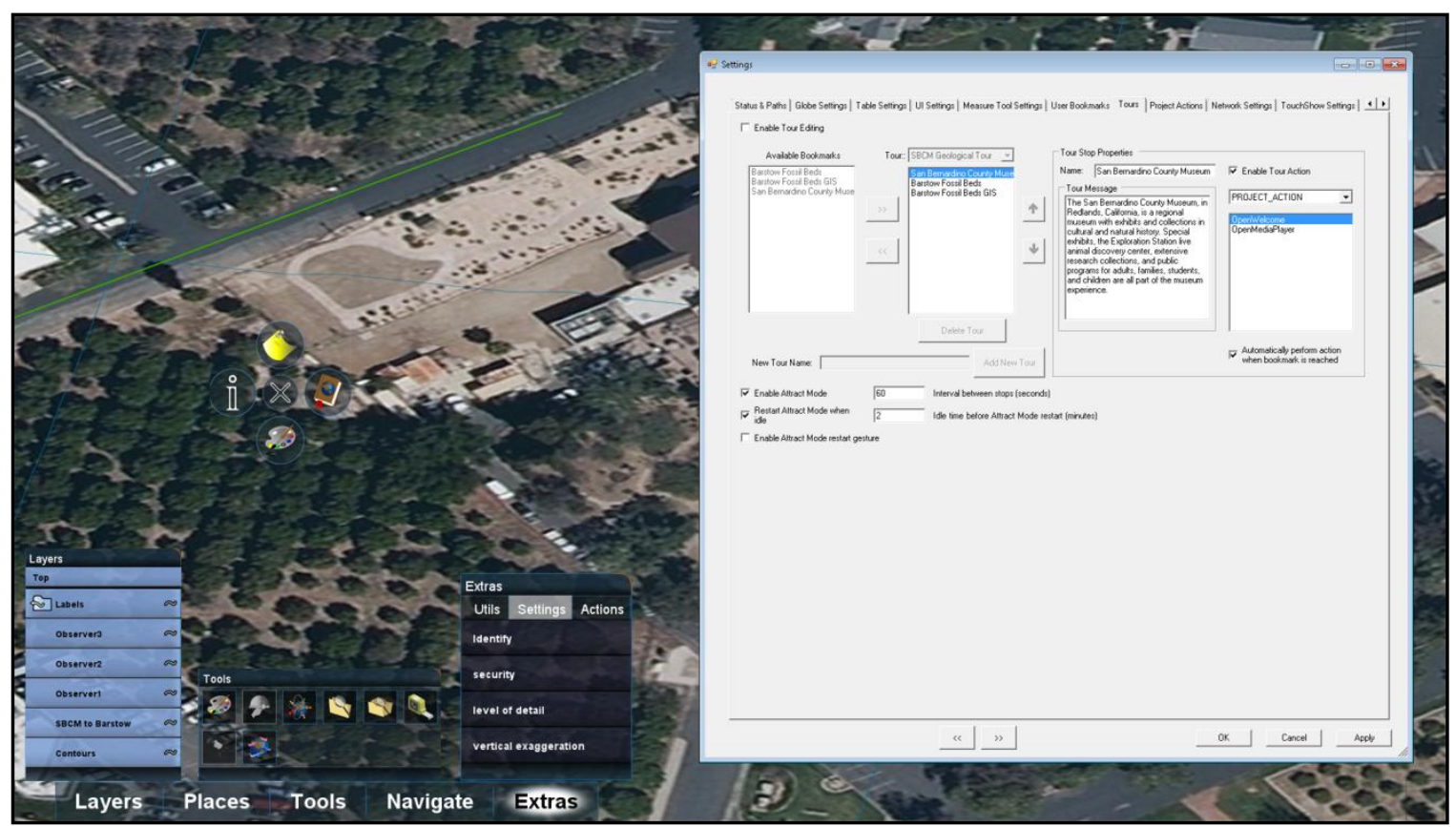

Figure 6-1: TouchShare GIS Software's Menus and Tools 
TouchShare GIS was developed to be used by experienced GIS users with sufficient training on the interface, and most of the system's users were not. The client requested modification to the user interface to show only Tour Toolbar, which allowed the users to navigate through the tour's geological area. However, the project team did not have the ability to make the changes because of the unavailability of TouchShare GIS's source code and the complexity of the changes. Therefore, the support staff at TouchTable was contacted to solve the user interface issue. The company was very cooperative and developed a new version of the software called TouchShare GIS - Kiosk Mode. The new version developed is the system's new user interface. All of the menus were removed except the Tour Toolbar, as shown in Figure 6-2. Both TouchShare GIS versions must be installed for the system to use them. The original version is used to configure the system's tour and save it as a document, and the kiosk version is used as the user interface by opening the created document. After these changes were made, a second demonstration was conducted for the client, who was pleased with the system's new user interface. 


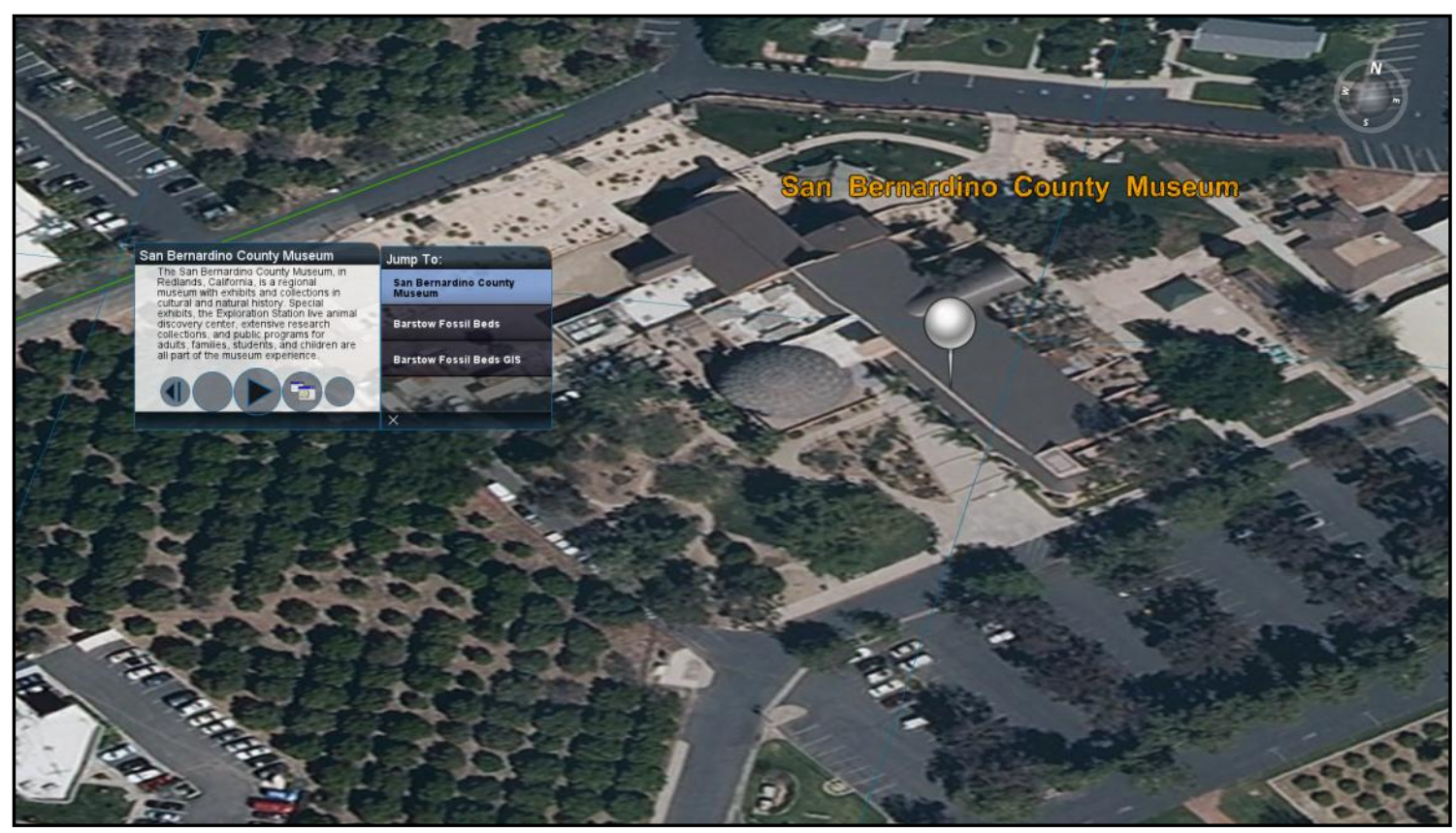

Figure 6-2: TouchShare GIS - Kiosk Mode

\subsection{The System's GIS Analyses}

During the first demonstration, the client requested changes in the interface, as well as the system's GIS analyses. The client was not interested in the contour lines, the viewshed analysis, and the network analysis being part of the tour. They thought it might complicate the system since most of the users are not experienced GIS users. However, the GIS analyses added more value to the presented information and the learning experience for the person using the system.

For example, the additional information provided enables the system's users to learn about the geological area's elevation by looking at the contour lines. The user can also identify the highest and the lowest points in a geological area by panning and zooming around to view the contour line values. (Figure 6-3 shows contour lines for an area in the system.) 


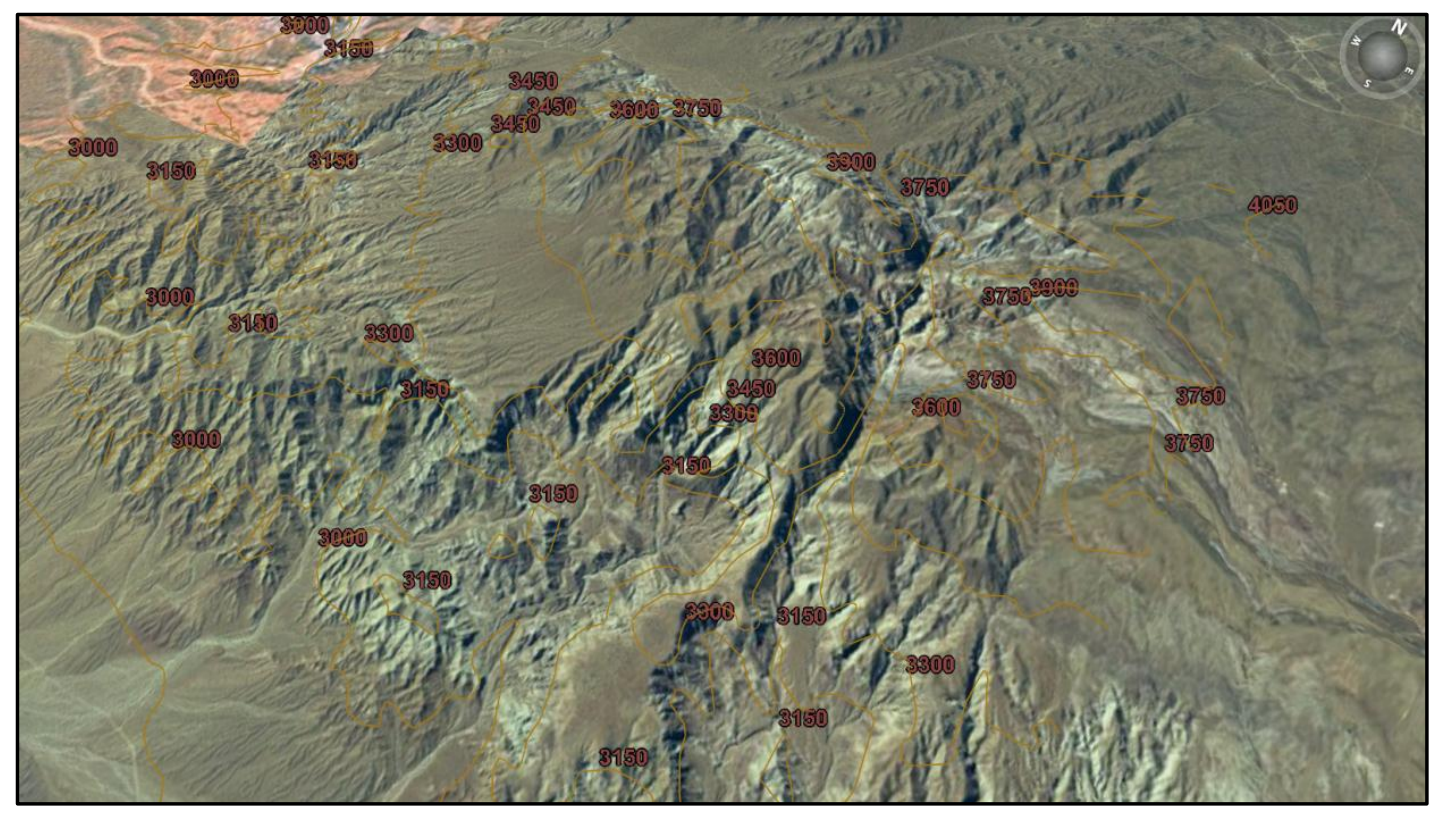

Figure 6-3: The System's Contour Lines

In addition, the viewshed results from different observer points within a geological area provide better visualization and insight into the area's topographical nature. The users even have the opportunity to compare the datasets to inspect why a certain area could not be seen from a particular observer point. (Figure 6-4 shows viewshed raster datasets in the system.) Moreover, the existing feature that provides the route from the museum to each of geological areas, including the expected drive time and the directions, may encourage the users to visit these areas. 


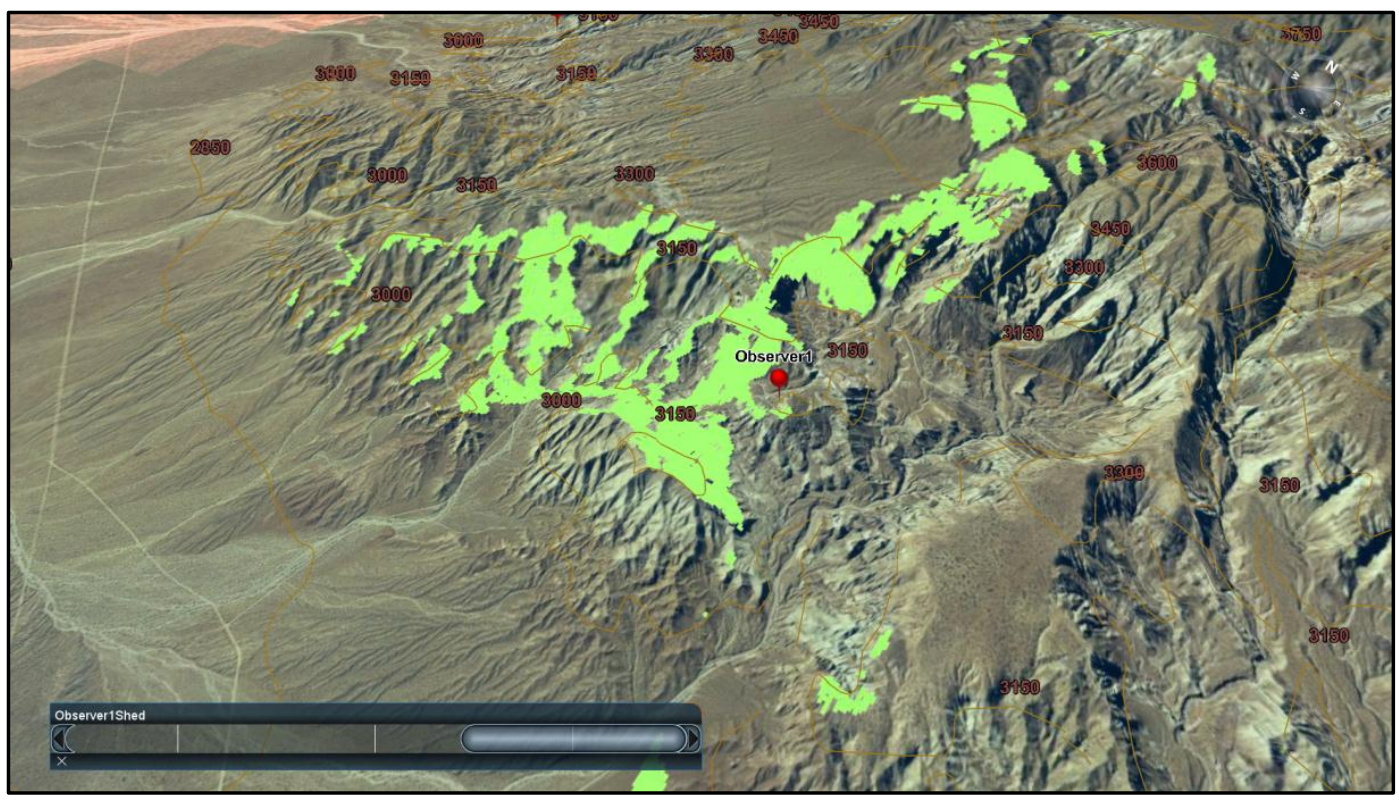

\section{Figure 6-4: The System's Viewshed Analysis}

None of these features requires GIS knowledge; the system presents them in a simple and interactive way that is easy to use. Furthermore, as a suggestion from the project team, the users can even examine the analyses and answer questions about the geological areas. The answers to questions can be found through studying the system's GIS results. For instance, a question about the highest elevation value or the highest observer point for a geological area can be answered by inspecting the contour lines. A user could compare the viewshed raster datasets to figure out which observer point provides the best view of an area. By providing the user with this additional information about the geological area, it is more likely that users will retain the knowledge gained during their visit to the museum. 


\subsection{Summary}

This chapter discussed the deployment process of the system and the result of the system's demonstration session with the client. The deployment process had some minor issues that were solved by updating TouchShare GIS and ArcGIS Desktop to the required versions. Then the system was demonstrated to the client as a part of the system training and to gather feedback. The client commented on two main parts of the system: the user interface and the GIS analyses. The user interface was complex and had many menus that might distract the user from using the system properly. A new version was developed, by TouchTable Inc., which allowed the user to only navigate through the tour. The other comment was about the system GIS analyses, which involved the contour lines, the viewshed analysis, and the routes to each geological area. The client was not interested in the GIS analyses and it thought they might confuse the users and complicate the system. The project team explained the benefits and clarified how this aspect provides more information about the geological areas. The team also suggested approaches to make the system's GIS results more interesting to the users. 



\section{Chapter 7 - Conclusions and Future Work}

This chapter concludes the project report. It discusses whether the project satisfied the system's functional and non-functional requirements or not. It also suggests some different ways to use the system. Finally, it proposes some new features and modification of existing features for the used software packages in the system that can enhance the performance of it.

\subsection{Conclusions}

The overall goal of this project was to use a new approach to present some of the geological exhibits of San Bernardino County in a way that would provide visitors and guests of the SBCM with a rich and interactive experience. To meet this goal, a system was developed by integrating three software packages. The first software package, ArcGlobe 9.3.1, works as GIS software for the system. ArcGlobe's integration with the system allows for a three-dimensional view of each geological feature on the tour. The second piece of software is the Tour Media Player, which was developed using Windows Presentation Foundation (WPF) 4.0. The player displays pictures and video about each geological area in a single, easy-to-use interface. The last piece of software is TouchShare GIS 6.2, which is the primary user interface. It provides users with two options: they can either navigate through the geological areas in a specific sequence, or they have the freedom to jump from one area to another. TouchShare GIS also displays prepared viewshed analysis results and routes from the museum to each area on the tour. The system runs on a personal computer that uses a multi-touch TouchTable as the input and output device. In addition to the system, a user manual was created to explain how to 
add new geological areas to the tour and how to operate the system. The system satisfied all of the functional and non-functional requirements that came from the client and the project committee.

\subsection{Future Work}

The current system architecture allows the system to only be used inside of the museum. However, through a simple modification, using a local ArcGIS Desktop license instead of the current network license, the system can be used outside of the museum. The museum may use it at conferences and exhibitions anywhere in the world. It can be moved to a location where people who are unable to visit the museum can enjoy it, such as a hospital or a retirement community. This would only require moving the system's hardware to the desired location and connecting it to the Internet, as shown in Figure 7-1.

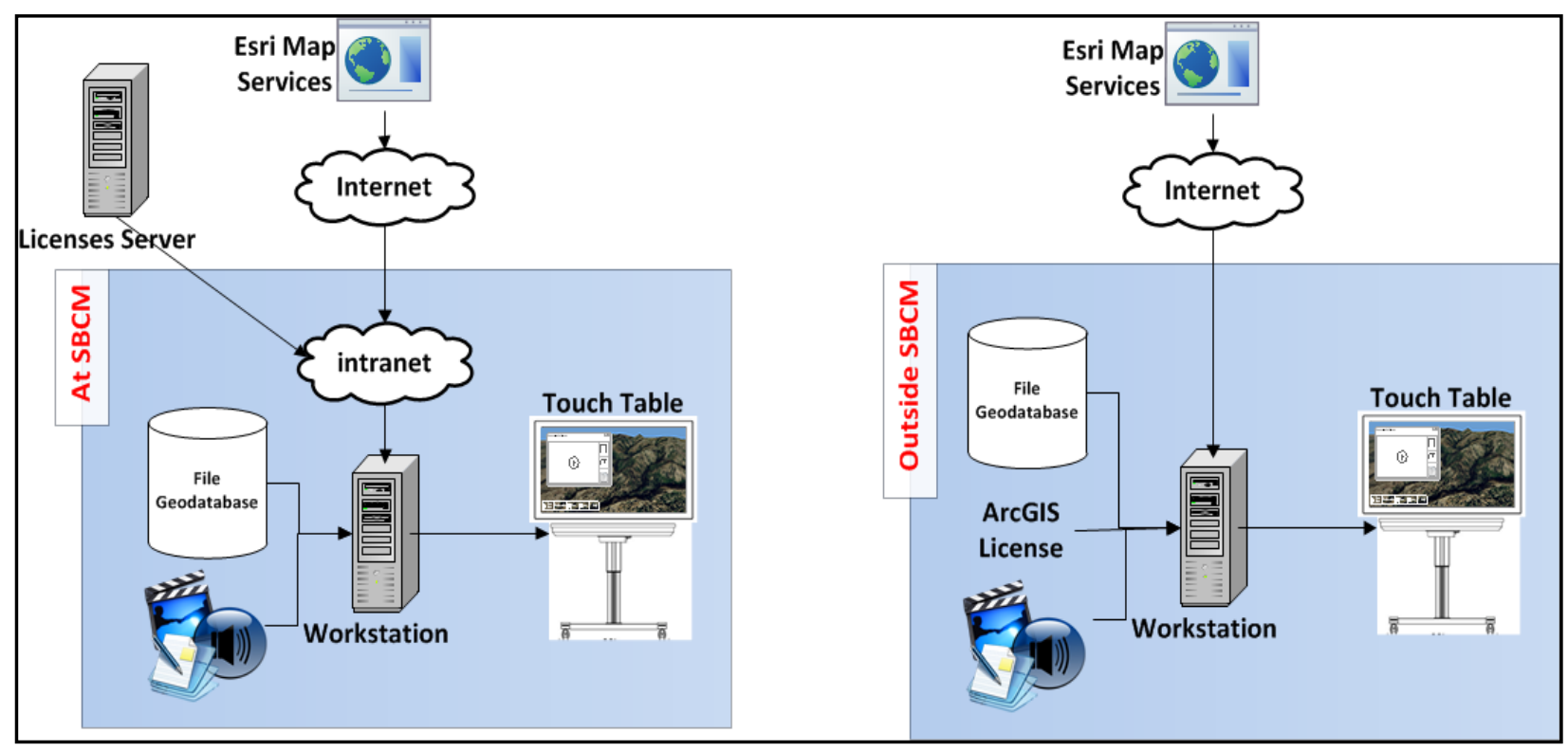

Figure 7-1: Comparison between the system architecture inside and outside the museum 
The system can also be used to present exhibited items in the museum, other than the geological areas on the tour. A virtual tour of the habitats of extinct plants and animal habitats in San Bernardino County, or the county's history, can be created without any modifications to the system.

Additional information can be included in the Multi-touch GIS-based Tour of San Bernardino Geological Wonders. For example, an analysis of the spatial pattern of the museum's fossil could be included. A study of the different types of the county's fossils, their locations, and the identification of any spatial patterns between the fossils can be initiated. The results of such research could be added to the tour as a layer that users can use to identify and view information.

Moreover, the project team suggests some additions and modifications in the software packages that have been used in the system which would enhance the performance. ArcGlobe's labeling engine needs enhancements; it does not apply specified labeling settings, as explained in Chapter Four. Furthermore, the tour flight movements could be enhanced. This could be achieved by adding a tool in ArcGlobe to allow a virtual flight between two bookmarks, using a feature line as a route to follow. The TouchShare GIS 6.2 must support the latest version of ArcGIS Desktop to utilize the most updated GIS functions and tools. It also could allow for the display of real-time data, such as an earthquake feed. It could also provide the ability to perform real-time GIS analysis, such as viewshed, line-of-sight, and network analysis. The TouchDrive 5.1 software acts as the translator between TouchTable's touch gestures and the operating system. It supports multi-touch gestures when using TouchShare GIS, but does not support Windows 7 native touch. This can allow the development of multi-touch 
applications by using technologies such as WPF 4.0 to employ the application in the Multi-touch GIS-based Tour of San Bernardino Geological Wonders.

\subsection{Summary}

The system is a new approach to help the San Bernardino County Museum present some geological areas in the form of a rich, interactive, virtual tour. The system satisfied all of the client's functional and non-functional requirements. It can be used inside and outside of the museum with a simple change. In addition, it allows for the creation of additional tours other than the geological tour. New information can always be added to the current tour, such as the result of spatial pattern analysis for the museum geological fossils.

By integrating GIS visualization into the realm of geology, the new system that has

been created for the San Bernardino County Museum will provide visitors with the ability to participate in hands-on learning as they explore these geological wonders. 


\section{Works Cited}

Ang, K. H., \& Wang, Q. (2006). A case study of engaging primary school students in learning science by using Active Worlds. First International LAMS Conference: Designing the Future of Learning (pp. 5-14). Sydney: The LAMS Foundation.

Barcelo, J. A. (2002). Virtual Museums. When Heritage does not exist. A Kozgyutemenyek es a tudomany "Public Collections and Science".

Boyd, P. D. (1999). GIS in Museums - A Case Study. In Access to Better Information. Association for Geographic Information. London, England: Association for Geographic Information.

Brodlie, K., \& El-Khalili, N. (2002). Web-based virtual environments. In P. Fisher, \& D. Unwin, Virtual Reality in Geography (pp. 35-46). London: Taylor \& Francis.

Correia, N., Mota, T., Nóbrega, R., Silva, L., \& Almeida, A. (2010). A multi-touch tabletop for robust multimedia interaction in museums. ITS '10 ACM International Conference on Interactive Tabletops and Surfaces (pp. 117-120). New York, US: ACM Press.

Elmasri, R., \& Navathe, S. B. (2004). Fundamentals of Database Systems (Fourth Edition ed.). New York: Pearson, Addison Wesley.

Esri. (2010, November 29). ArcGIS Desktop 9.3 Help. Retrieved June 6, 2012, from Simplify Line (Data Management):

http://webhelp.esri.com/arcgisdesktop/9.3/index.cfm?TopicName=Simplify_Line _(Data_Management)

Esri. (2010, May 27). Types of Geodatabases. Retrieved May 24, 2012, from ArcGIS Desktop 9.3 Help: 
http://webhelp.esri.com/arcgisdesktop/9.3/index.cfm?TopicName=Types_of_geod atabases

Esri. (July 2004). ArcGIS® $3 D$ Analyst ${ }^{\mathrm{TM}} —$ Designing Interactive ArcGlobe ${ }^{\mathrm{TM}}$ Documents. Redlands, CA: Esri Press.

Faust, N. (1995). The Virtual Reality of GIS. Environment and Planning B: Planning and Design, 22, 257-268.

Fisher. (1996, November 11). Extending the Applicability of Viewsheds in Landscape Planning. Photogrammetric Engineering \& Remote Sensing, 62(11), pp. 12971302.

Fisher, P., \& Unwin, D. (2002). Virtual Reality in Geography An Introduction. In P. Fisher, \& D. Unwin, Virtual Reality in Geography (p. 1). London: Taylor \& Francis.

Garcia-Milagros, E., \& Funk, V. (2010). Improving the use of information from museum specimens: Using Google Earth $\odot$ to georeference Guiana Shield specimens in the US National Herbarium. The International Biogeography Society, 71-77.

Geller, T. (Sept/Oct 2006). Interactive Tabletop Exhibits in Museums and Gallaries. Computer Graphics and Applications, 26(5), 6-11.

Haklay, M. (2002). Virtual reality and GIS: Applications, trends and directions. In P. Fisher, \& D. Unwin, Virtual Reality in Geography (pp. 47-57). London: Taylor \& Francis.

Hirose, M. (2006). Virtual Reality Technology and Museum Exhibit. The International Journal of Virtual Reality, 31-36. 
Huang, Jiang, \& Li. (2001). An Integration of GIS, Virtual Reality and the Internet for Visualization, Analysis and Exploration of Spatial Data. Geographical Information Science, 15(5), 439-456.

Hut, P. (2007). Virtual Laboratories. Progress of Theoretical Physics, 38-53.

Koller, D., Lindstrom, P., Ribarsky, W., Hodges, L., \& Faust, N. (1995). Virtual GIS: A Real-Time 3D Geographic Information System. Visualization '95 (pp. 94-100). Atlanta, GA: IEEE.

Lepouras, G., \& Vassilakis, C. (2004). Virtual Museums for All: Employing Game Technology for Edutainment. Virtual Reality, 8(2), 90-106.

Lin, H., \& Batty, M. (2009). Virtual Geographic Environments: A Primer. In H. Lin, \& M. Batty, Virtual Geographic Environments (p. 1). Beijing: Science Press.

Llobera, M. (2003). Extending GIS-based visual analysis: the concept of visualscapes. International Journal of Geographical Information Science, 17(1), 24-48.

Martin, J. (1991). Rapid application development. Indianapolis, IN, USA: Macmillan Publishing Co.

Michael, D., Pelekanos, N., Chrysanthou, I., Zaharias, P., Hadjigavriel, L. L., \& Chrysanthou, Y. (2010). Comparative Study of Interactive Systems in a Museum. EuroMed'10 Proceedings of the Third international conference on Digital heritage (pp. 250-261). Berlin: Springer.

Michael, D., Zaharias, P., \& Chrysanthou, Y. (2010). A Virtual Tour of the Walls of Nicosia: An Assessment of Children Experience and Learning Performance. VAST10: The 11th International Symposium on Virtual Reality, Archeology and Intelligent Cultural Heritage (pp. 9-15). Paris, France: Eurographics Association. 
Nijholt, A. (2000). Agent-supported Cooperative Learning Environments. International Workshop on Advanced Learning Technologies (IWALT 2000) (pp. 17-18). Palmerston North, New Zealand: IEEE Computer Society Press.

Richards, J. D. (1998). Recent Trends in Computer Applications in Archaeology. Journal of Archaeological Research, 331-382.

Schoning, J. (2010). Touching the future: the rise of multitouch interfaces. PerAda Magazine.

Springer, K. (n.d.). The Hall of Geological Wonders. (S. B. Museum, Interviewer)

Tobler, W. (1979). A Transformational View of Cartography. The American Cartographer, 6(2), pp. 101-106.

Tomlinson, R. (2011). Thinking about GIS. Redlands, California: Esri Press.

Tsichritzis, D., \& Gibbs, S. (1991). Virtual Museums and Virtual Realities. International Conference on Hypermedia \& Interactivity in Museums (pp. 17-25). Pittsburgh, PA: Archives \& Museum Informatics.

van Maren, G., Germs, R., \& Jansen, F. (1998). Integration 3D-GIS and Virtual Reality Design and Implementation of the Karma VI System. 10th Colloquium of the Spatial Information Research Center (pp. 343-352). Otago, New Zealand: Colloquium of the Spatial Information Research Center.

van Woert, A. (2011). GIS Use in the Reinterpretation of Archaeological Museum Collections: The Coombs site, Boulder, Utah. Chico, CA: California State University, Chico.

Zlatanova, S., Rahman, A. A., \& Pilouk, M. (2002). Trends in 3D GIS Development. Journal of Geospatial Engineering, 4(2), 71-80. 


\section{Appendix A. Operational Manual}

This is the operational manual for the Multi-touch GIS-based Tour of San Bernardino

Geological Wonders. Before starting with the manual, make sure that the following software packages were installed on San Bernardino County Museum's workstation:

ArcGIS Desktop 9.3.1, TouchShare GIS 6.2, and the Tour's Media Player. Moreover, be sure that the system ArcGlobe document, which represents the tour's geological areas, and the system geodatabase are stored in the same workstation.

This manual explains how to add new media files to the Tour's Media Player, how to link TouchShare GIS with the player, and how to configure a new tour using TouchShare GIS.

The Tour's Media Player has a configuration file, which resides in its program directory. The file is responsible for maintaining the locations of the media files (pictures and video) for each geological area. Figure A.1 show part of the file.

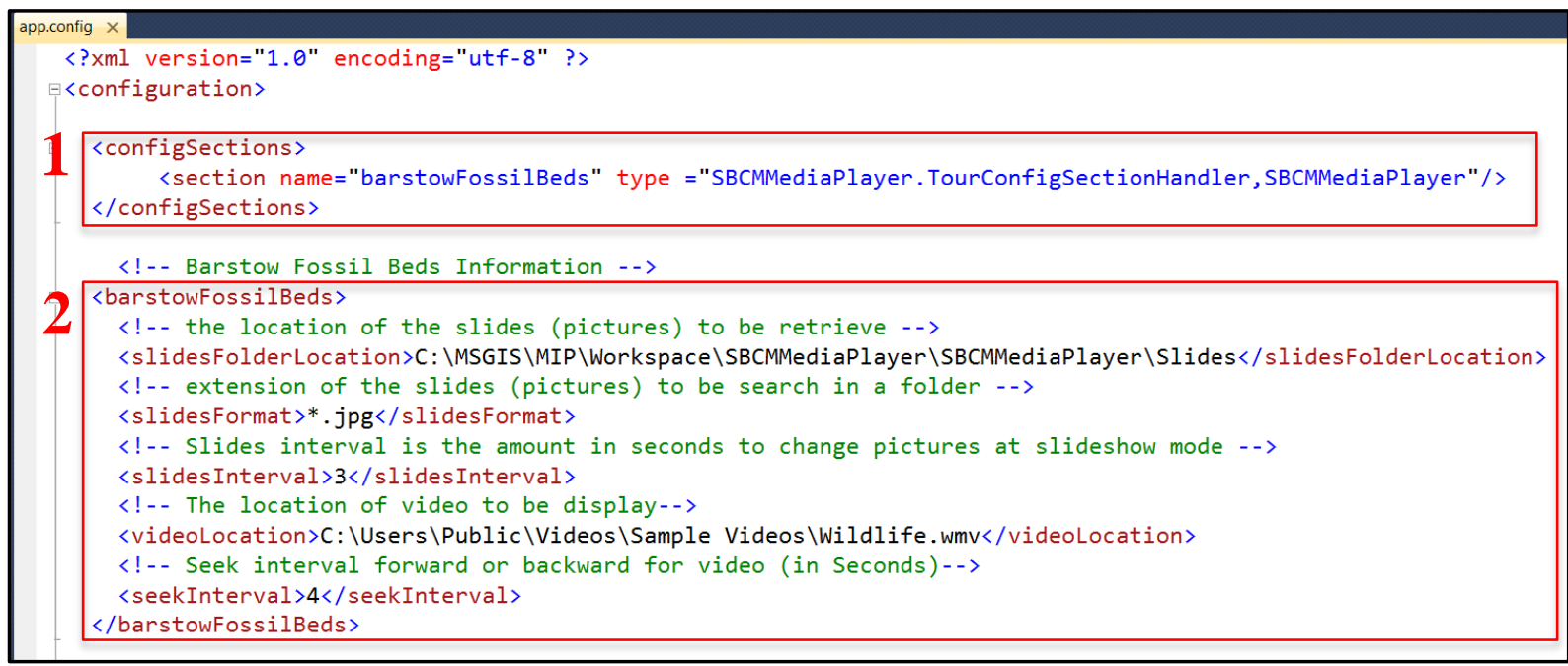

Figure A- 1: Part of the Tour's Media Player Configuration File 
To add new geological area's media files to the tour, do the following steps:

1. At "<configsections>", add a new entry as shown in the example below: <section name="deathvalley" type ="SBCMMediaPlayer.TourConfigsectionHandler, SBCMMediaPlayer"/>

2. Then add a new section below "<configsections>". The new section should be started between two tags with the same name as the new geological area name. Example:

“<deathvalley>

$</$ deathValley $>$

3. In the new sections, five different parameters must be set as follows:

a. <slidesfolderLocation>: the location of the folder of the slides (pictures) of a geological area. All the slide's name must start with a number which represents the sequence of the slides to be shown in the player.

b. 〈slidesFormat>: the extension of the slides (pictures) in the folder. All the slides must have same extension format.

c. 〈slidesInterval>: is the amount in seconds to change slides at slideshow mode.

d. 〈videoLocation>: the location of the video of a geological area.

e. <seekInterval>: seek interval forward or backward for the video in seconds.

The following code is an example of setting the five parameters.

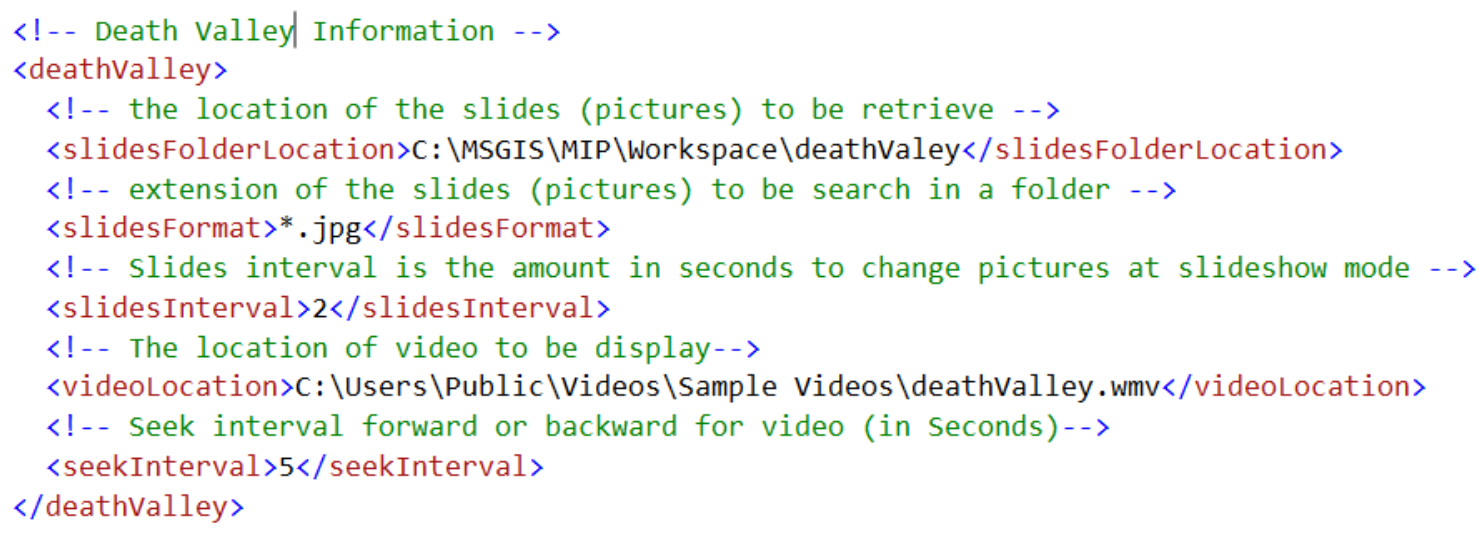


The following code shows an example of the configuration file after adding the new geological area's media files.

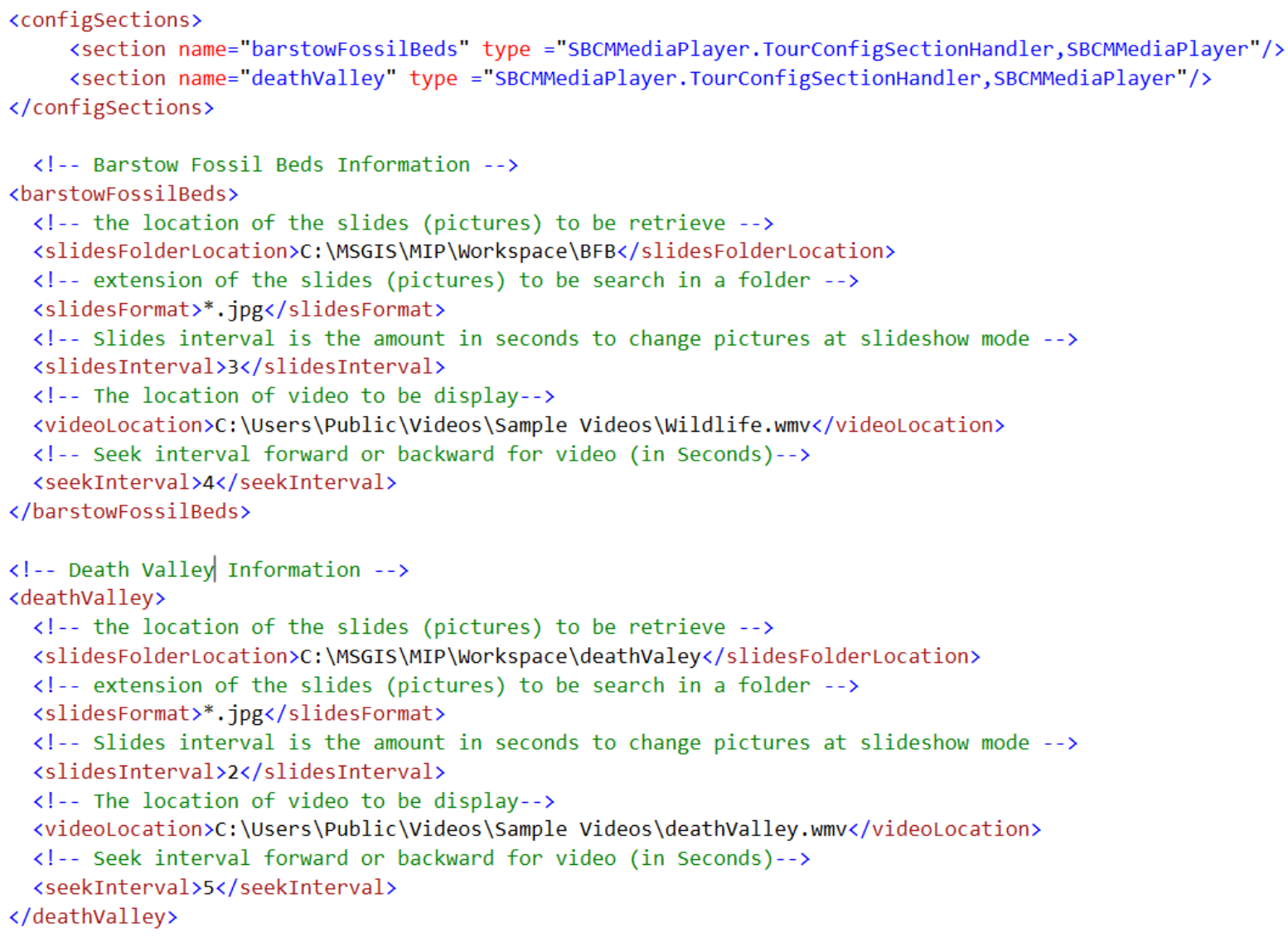

After configuring the Tour's Media Player, a link between TouchShare GIS and the player should be created. This link will allow the player to automatically open when the tour reaches a geological area. The following steps explain how to configure the link:

1. At the Windows taskbar, click Start, then All Programs, select TouchTable folder and open Settings Editor program.

2. In the Settings Editor dialog, go to the Globe Settings tab. Then, click on the Browse button and choose the Multi-touch GIS-based Tour of San Bernardino Geological Wonders' ArcGlobe document. 
3. Next, click on File then choose Save at Settings Editor dialog toolbar and select a directory to save TouchShare GIS document.

4. Open the TouchShare GIS document of the tour. Then, at the main toolbar, open Extra menu, select Settings, and choose open dialog option. As shown in Figure A.2.

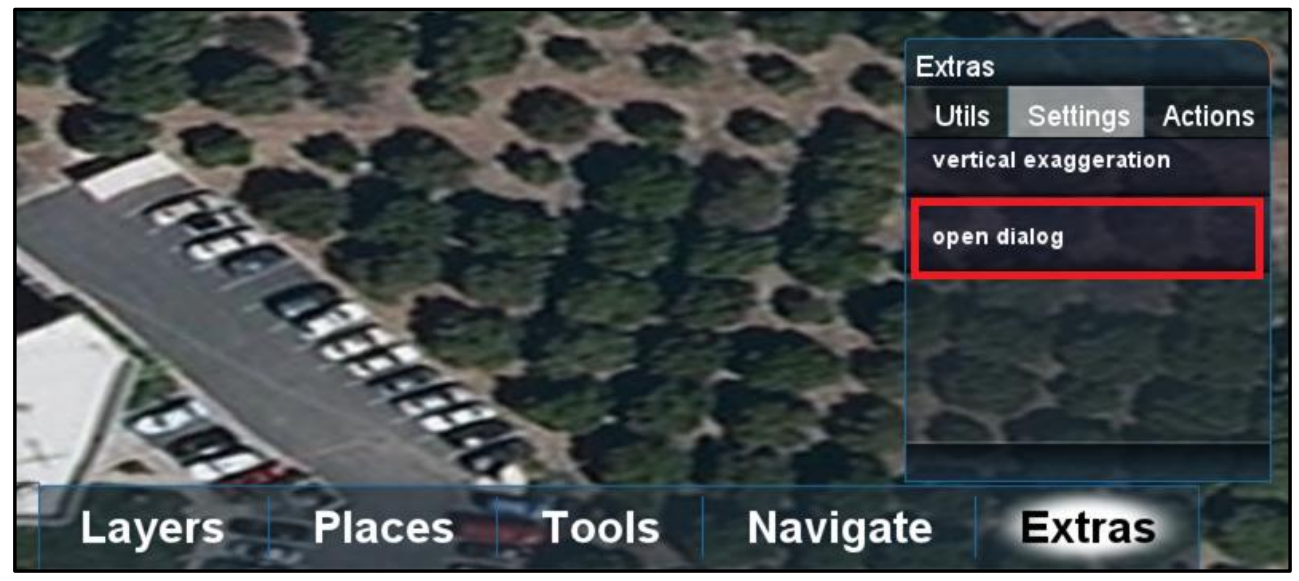

Figure A- 2: TouchShare Extra Menu

5. In the Settings dialog, go to Project Actions tab. The tab shows the required settings to create custom actions, which is executed when the tour reaches a bookmark (geological area). First, the name of the action should be set. Then, the Tour's Media Player executable file should be located in the Program Path text box. Finally, the Program Argument text box should be filled with the name of a geological area that was specified in the player configuration file, for example, "barstowFossilBeds" or “deathValley". Figure A.3 shows how to fill the settings of Project Actions tab. 


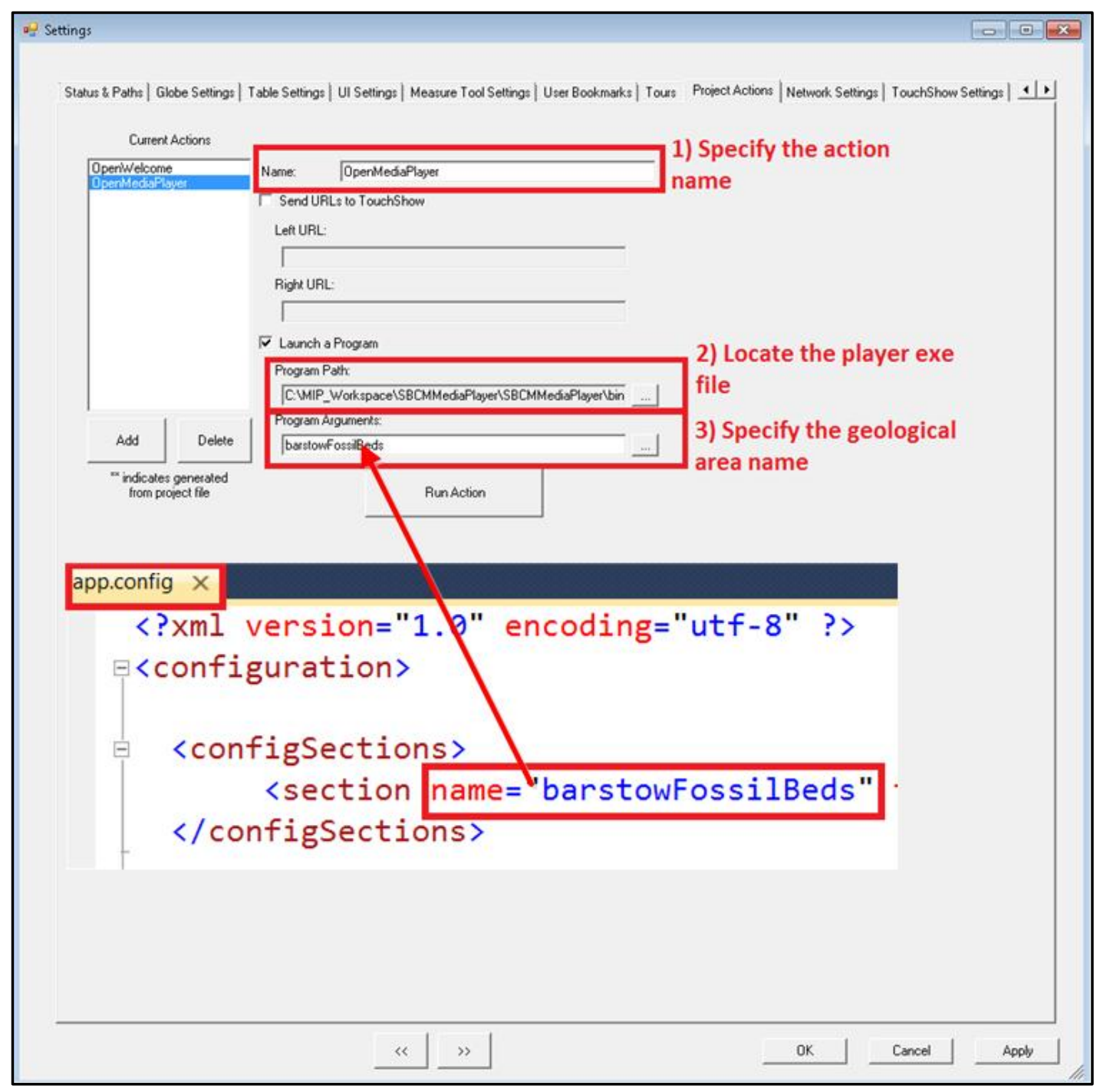

Figure A- 3: Project Actions settings

6. Each geological area should have an action to start the player with the associated media files to that area. Thus, step 5 should be repeated for each geological area.

After linking TouchShare GIS with Tour's Media Player, the tour can be configured using the Settings dialog, Tours tab. The following steps show the configuration process: 
1. Figure A.4 shows how to configure a tour. First, in the New Tour Name text box, write the name of the tour and click Add New Tour button.

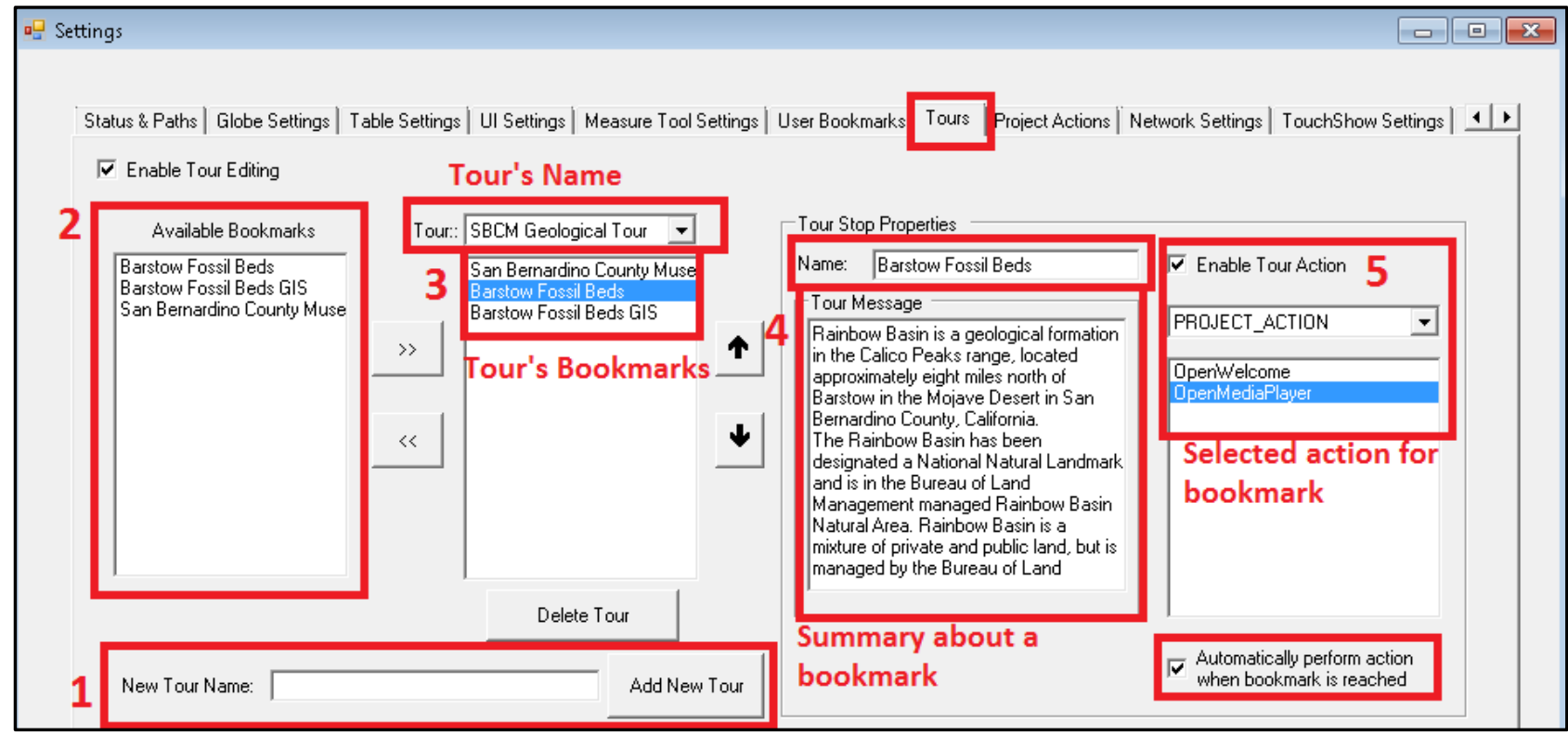

\section{Figure A- 4: Configuring the Tour's Settings}

2. Then, from the Available Bookmarks list, select the bookmarks that are associated with the geological areas and move them to the Tour's Bookmarks list.

Note: the Available Bookmarks list is created from the system ArcGlobe document's bookmarks. Moreover, additional bookmarks can be added to the list by adding bookmarks from TouchShare GIS. For more details of how to add bookmarks in TouchShare GIS software, review TouchShare GIS user manual.

3. Select a bookmark form the Tour's Bookmarks list, then write a summary about the geological area in the Tour Message text box.

4. Check the Enable Tour Action checkbox, and select PROJECT_ACTION from dropdown box. Then, a list of the created actions will be shown; select the action that was created to start the media player for the selected geological area. 
5. Repeat steps 3 and 4 for each of the tour's geological areas. Finally, click on the OK button of the Settings dialog. 